\title{
Study of Gypsum Plasters Exposed to Fire
}

\author{
J. V. Ryan
}

(June 5, 1962)

\begin{abstract}
Experimental results are reported from a study in which small gypsum plaster specimens were exposed to controlled fires similar to those to which large building elements have been subjected in tests by a recognized standard method. The small specimens were tested without either structural load or restraint. Their fire performances were judged on time to a temperature rise criterion. The results were analyzed to determine the effects on fire performance of variation of mix ratio, aggregate type and density, duration of aging, and relative humidity of the ambient in which the specimens were aged. Mix ratio and aggregate density, over the ranges normally used, had little effect, if any, on fire performance. The times to temperature rise for perlite and vermiculite aggregate plasters were essentially equal, but shorter times were observed for sanded plasters. Duration of aging and relative humidity of the ambient had a significant effect only for short aging periods and very high relative humidity conditions.

Estimates of thermal properties of gypsum plasters at elevated temperatures were derived from the data. These estimates should be useful for predicting fire endurances of building elements involving gypsum plaster.
\end{abstract}

\section{Introduction}

Prehistoric man probably plastered the interior of his stick-and-grass hut with mud. Gypsum plaster, ${ }^{1}$ similar to that of today, was used in Egyptian pyramids and tombs at least 4,000 years ago; white lime plaster was used in Greece 3,000 years ago, and by the Romans later. It is not clear that any of the advanced civilizations of Egypt, Greece, or Rome recognized the value of plaster as a fire protective material. In more recent times, official recognition included an Ordinance by King John, following the London fire of 1212, in which plastered walls were required in certain buildings [1]. ${ }^{2}$ Although plaster has been used extensively for fire protection through the years, the particular application was based more on accumulated experience than on the results of planned investigations, until comparatively recent times. Even today much of the data available on the fire protection of structures with plaster was derived from isolated tests conducted for "approval" purposes, rather than from systematic study.

A number of cementitious materials are employed in the plastering of building elements. Among these are gypsum, portland cement, lime, and various combinations. Gypsum neat plaster consists of not less than 66 percent of hemihydrate calcium sulfate $\left(\mathrm{CaSO}_{4} \cdot \frac{1}{2} \mathrm{H}_{2} \mathrm{O}\right)$ plus other materials added at the factory to control time of set and working qualities. When mixed with water, the gypsum changes to $\mathrm{CaSO}_{4} \cdot 2 \mathrm{H}_{2} \mathrm{O}$, making the hard plaster of wide use. Under fire exposure, the fully hydrated gypsum is calcined, or changed back to hemihydrate, at about $260{ }^{\circ} \mathrm{F}$ and to anhydrous $\mathrm{CaSO}_{4}$ at about $350{ }^{\circ} \mathrm{F}$.

${ }^{1}$ In accordance with established technical and practical usage, the term plaster is used in this paper for both the dry, powdery material sold on the market and the hardened end product resulting from chemical reaction with water, with or without aggregate.

2 Figures in brackets indicate the literature references at the end of this paper.
Both these phase changes are endothermic. Also, the chemically combined water released, representing 21 percent by weight of the original material, plus additional free water ordinarily present is vaporized. Consequently, great quantities of heat are absorbed without causing temperature increases during the calcination of gypsum. This fact makes gypsum plaster an important material for the fire protection of buildings.

The present study on gypsum plasters consisted of an experimental program on the fire endurances of small plaster specimens plus determinations of thermal conductivity and other physical properties. The plasters represented a variety of aggregate and mix combinations. The data obtained were analyzed to make comparisons among the plasters in terms of fire endurance and to make estimates of their thermal properties at elevated temperatures, both useful for predicting the fire endurance of building elements involving gypsum plaster.

\section{Investigation}

Several factors affect the behavior of a plastered building element when exposed to fire. Some, such as method of attachment between plaster and structural elements, are characteristic of the assembly. Others, such as mix proportions and aggregate type, are characteristic of the plaster itself. The former were eliminated as far as possible for the experiments reported here.

\subsection{Factors Varied}

The investigation was designed to provide comparative data on the effects of four factors, as well as the interactions among them. The factors were:

A. Aggregate. Three different aggregates were used: perlite, vermiculite, and sand. In addition, 
the perlites used were in three density ranges, designated as high, intermediate, and low.

B. Mix. The mixes chosen included those in common use plus some leaner and some richer in gypsum content.

C. Length of aging. The length of aging period prior to the fire test was varied from 28 to 103 days.

D. Humidity. Each specimen was aged at room temperature in air at either high or intermediate relative humidity.

\subsection{Specimens}

Three sizes of specimens were prepared: those for fire tests, those for thermal conductivity determinations, and those for compressive strength tests. Each fire-test specimen consisted of approximately 1 in. of plaster applied to a 24-in. square base of metal lath. Each thermal-conductivity specimen was a 1 - by 8 - by 8 -in. slab of plaster; each compressive-strength specimen, a 2 -in. cube of plaster. The specimens were made in sets, each set consisting of two fire-test specimens, two thermal-conductivity specimens, and either three or six cubes for compressive strength determinations. All the specimens except two sets were prepared by the same experienced craftsman, whose work was excellent. The forms for specimens are shown in figure 1 .

\section{a. Materials}

The plasters were all regular commercial gypsum plasters and complied with the requirements of ASTM C-28; that for all but one set of the sanded mixes was unfibered; those for the lightweight aggregate mixes were extra fibered (sisal) and formulated for use with lightweight aggregates. The program was started with a supply of the latter type all from a single production lot at one plant. This proved

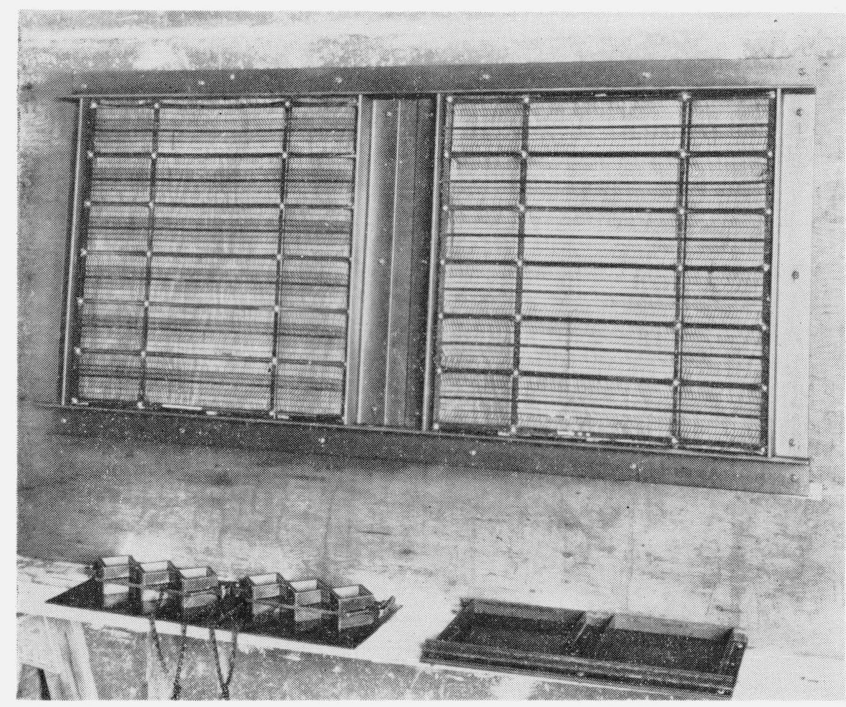

Figure 1. Specimen forms: upper, for fire test specimens, with two lath-and-channel assemblies in place; lower left, for 2-in. cubes; lower right, for 8-by 8-by 1-in. specimens.
TABLE 1. Data on aggregates

\begin{tabular}{l|c|c|c|c}
\hline \hline & \multicolumn{3}{|c|}{ Perlite } & Vermic- \\
ulite
\end{tabular}$\quad$ Sand

DENSITY, lb $/ \mathrm{ft}^{3}$

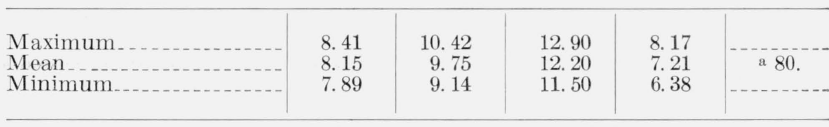

SIEVE ANALYSIS

\begin{tabular}{|c|c|c|c|c|c|}
\hline \multirow{2}{*}{ Sieve No. } & \multicolumn{4}{|c|}{ Accumulated percent retained } & \multirow{2}{*}{$\begin{array}{c}\mathrm{By} \\
\text { weight }\end{array}$} \\
\hline & \multicolumn{4}{|c|}{ By volume } & \\
\hline 4 & 0.0 & 0.0 & 0.0 & 0.0 & 0.6 \\
\hline 8 & .2 & .2 & .2 & 3. 4 & 4. 5 \\
\hline 16 & 19.2 & 20.6 & 21. 6 & 47. 7 & 11.0 \\
\hline 30 & 49. 6 & 56.4 & 67.3 & 85.3 & 28.3 \\
\hline 50 & 83.9 & 86.7 & 92.7 & 95.9 & 88.2 \\
\hline 100 & 95.5 & 96.2 & 98.5 & 99.2 & 96.8 \\
\hline Pan & 100.0 & 100.0 & 100.0 & 100.0 & $\begin{array}{r}90.0 \\
100.0\end{array}$ \\
\hline
\end{tabular}

FINENESS MODULUS

\begin{tabular}{l|l|l|l|}
2.48 & 2.60 & 2.81 & 3.31
\end{tabular}

2. 29

a Dry weight of $1 \mathrm{ft}^{3}$ of damp sand, average value.

to be an inadequate supply and a supplementary supply was obtained. The plaster for lightweight aggregates proved unsatisfactory with sand aggregate, so the unfibered gypsum plaster was obtained. The hemihydrate content of the initial supply was 88.4 percent, that of the supplementary supply 85.7 percent. The unfibered gypsum plaster for use with sand was not analyzed.

The aggregates were sand, perlite, and vermiculite. The sand was from the White Marsh pits. This sand, known to be highly siliceous, was received with a minor amount of small gravel. It was sieved to remove this gravel, placed in fiber drums, and stored indoors. The moisture content was 2.1 percent upon receipt. One set of specimens was made with the sand at the original moisture content using extra fibered plaster. The moisture content of the sand was less than 0.2 percent by the time the unfibered gypsum plaster had been obtained for the remainder of the specimens.

The perlite aggregates from an ore deposit near Grants, N. Mex., were provided in three density ranges: low, intermediate, and high, varying from 8 to $13 \mathrm{lb} / \mathrm{ft}^{3}$. The intermediate density perlite was reported as representative of normal production. The perlites were received in fiber drums and stored indoors. The vermiculite was obtained in paper bags from a local building supply firm and was stored indoors. Densities, sieve analyses, and fineness moduli for the various aggregates are given in table 1 .

The water was drawn from the municipal supply into clean buckets for weighing and dumped into the mixer. The metal lath and furring channels were standard commercial products. 


\section{b. Mixes}

The proportions of the plasters with perlite or vermiculite are expressed as bags (nominally 99.25 $\mathrm{lb}$, about $1.5 \mathrm{ft}^{3}$ ) of gypsum to volume of aggregate in cubic feet; those of the sanded plasters are expressed as weight of gypsum to the dry weight of the sand. The amount of water used was determined by the "workability" as judged by the plasterer. The various mixes prepared are listed in table 2.

All constituents of each mix were weighed. The usual charge for a batch of lightweight aggregate plaster consisted of one cubic foot of agogregate and the proper weight of gypsum based on nominal $99.25 \mathrm{lb}$ per bag. Each batch was mixed $2 \frac{1}{2} \mathrm{~min}$ after the last water was added. Data on the mean mix proportions are given in table 2 .

\section{c. Preparation of Specimens}

The plaster bases, details of which are shown in figure 2, for two fire-test specimens were prepared with temporary nonabsorbent backing behind and braced against the lath. The backing produced a smooth rear surface, thereby facilitating reliable average thickness measurements that could not have been obtained with the usual "keyed" rear surface. The two plaster bases were placed in a frame, shown with the forms for other specimens in figure 1, which was mounted in a nearly vertical position. The plaster, aggregate, and water were mixed in a $4 \mathrm{ft}^{3}$ capacity commercial plaster mixer. The resulting wet mixture was applied to the metal lath base by trowel, the surface struck off with a metal "featheredge" and, after partial set had developed, was again troweled to produce as smooth a surface as practicable. Except for specimens of $1: 2,1: 3$ mixes $(\mathrm{E}, \mathrm{E}-\mathrm{L}, \mathrm{E}-\mathrm{H}$ in tables 2 and 3 ) that required two-coat application, the full thickness of the lightweight aggregate plaster specimens was built up in a single continuous application. The sanded plaster, being considerably heavier, tended to slump so that two-coat applications, both of the same mix, were necessary. In all two-coat applications, the first coat was scratched with a wire brush. The second coat was not applied until the following day, although the first usually set within a few hours.

The thermal-conductivity specimens were prepared by placing in each form an amount of plaster estimated at about half that required to fill the form, with an attached vibrator in operation. More plaster was added, care being taken to eliminate, so far as possible, air pockets. The top surface was struck off and troweled.

The compressive-strength specimens were made by partially filling the forms with plaster, attempting to eliminate air pockets, filling, and striking off the top surface.

\section{d. Aging}

As soon as the troweling of the specimens was finished, they were covered with wet burlap. The next day they were removed from the forms and placed in the conditioning rooms, at which time the temporary backing was removed from the fire-test specimens. From each set, generally, one fire-test specimen and one thermal-conductivity specimen were placed in a high relative humidity box. The other fire-test and thermal-conductivity specimens

TABLE 2. Mix information

Based on mean values for materials used in preparing from one to eight batches of the various mixes

\begin{tabular}{l|c|c|c|c}
\hline \hline \multirow{2}{*}{ Designation } & $\begin{array}{c}\text { Nominal } \\
\text { mix a }\end{array}$ & Gypsum-to-aggregate ratio & $\begin{array}{c}\text { Water-to-gyp- } \\
\text { sum ratio by } \\
\text { weight }\end{array}$ & $\begin{array}{c}\text { Compressive } \\
\text { strength }\end{array}$ \\
\cline { 3 - 5 } & By weight & By volume &
\end{tabular}

\begin{tabular}{|c|c|c|c|c|c|}
\hline \multicolumn{6}{|c|}{ No aggregate } \\
\hline A & Neat & 1:0 & $1: 0$ & 0.36 & $\begin{array}{c}p s i \\
2440\end{array}$ \\
\hline \multicolumn{6}{|c|}{ Perlite aggregates } \\
\hline $\begin{array}{l}\text { B } \\
\text { C } \\
\text { D } \\
\text { D-L b } \\
\text { D-H b } \\
\text { E- } \\
\text { E-L b } \\
\text { E-H b } \\
\text { F }\end{array}$ & $\begin{array}{l}1: 1 \\
1: 2 \\
1: 21 / 2 \\
1: 21 / 2 \\
1: 21 / 2 \\
1: 2,1: 3 \\
1: 2,1: 3 \\
1: 2,1: 3 \\
1: 4\end{array}$ & $\begin{array}{l}1: 0.10 \\
1: 0.20 \\
1: 0.24 \\
1: 0.21 \\
1: 0.32 \\
1: 0.21,1: 0.31 \\
1: 0.16,1: 0.24 \\
1: 0.24,1: 0.34 \\
1: 0.38\end{array}$ & $\begin{array}{l}1: 0.67 \\
1: 1.33 \\
1: 1.67 \\
1: 1.67 \\
1: 1.67 \\
1: 1.33,1: 2 \\
1: 1.33,1: 2 \\
1: 1.33,1: 2 \\
1: 2.67\end{array}$ & $\begin{array}{c}0.45 \\
.59 \\
.66 \\
.64 \\
.69 \\
.59,0.80 \\
.59,0.80 \\
.60,0.80 \\
.87\end{array}$ & $\begin{array}{c}1460 \\
1020 \\
860 \\
910 \\
790 \\
1120,440 \\
1000,510 \\
960,490 \\
460\end{array}$ \\
\hline \multicolumn{6}{|c|}{ Vermiculite aggregate } \\
\hline$G_{\ldots \ldots \ldots}$ & $1: 21 / 2$ & $1: 0.18$ & $1: 1.67$ & 0.95 & 320 \\
\hline \multicolumn{6}{|c|}{ Sand aggregate } \\
\hline $\begin{array}{l}\mathrm{H}_{-} \\
\mathrm{J}_{\ldots}\end{array}$ & $\begin{array}{l}1: 2 \\
1: 4\end{array}$ & $\begin{array}{l}1: 2 \\
1: 4\end{array}$ & $\begin{array}{l}1: 1.67 \\
1: 3.33\end{array}$ & $\begin{array}{r}0.65 \\
.86\end{array}$ & $\begin{array}{r}1050 \\
390\end{array}$ \\
\hline
\end{tabular}

a Mixed units-bags of gypsum to cu ft of lightweight aggregates; by weight, for sand aggregate.

b $\mathrm{L}=$ low-density perlite, $\mathrm{H}=$ high-density perlite. 


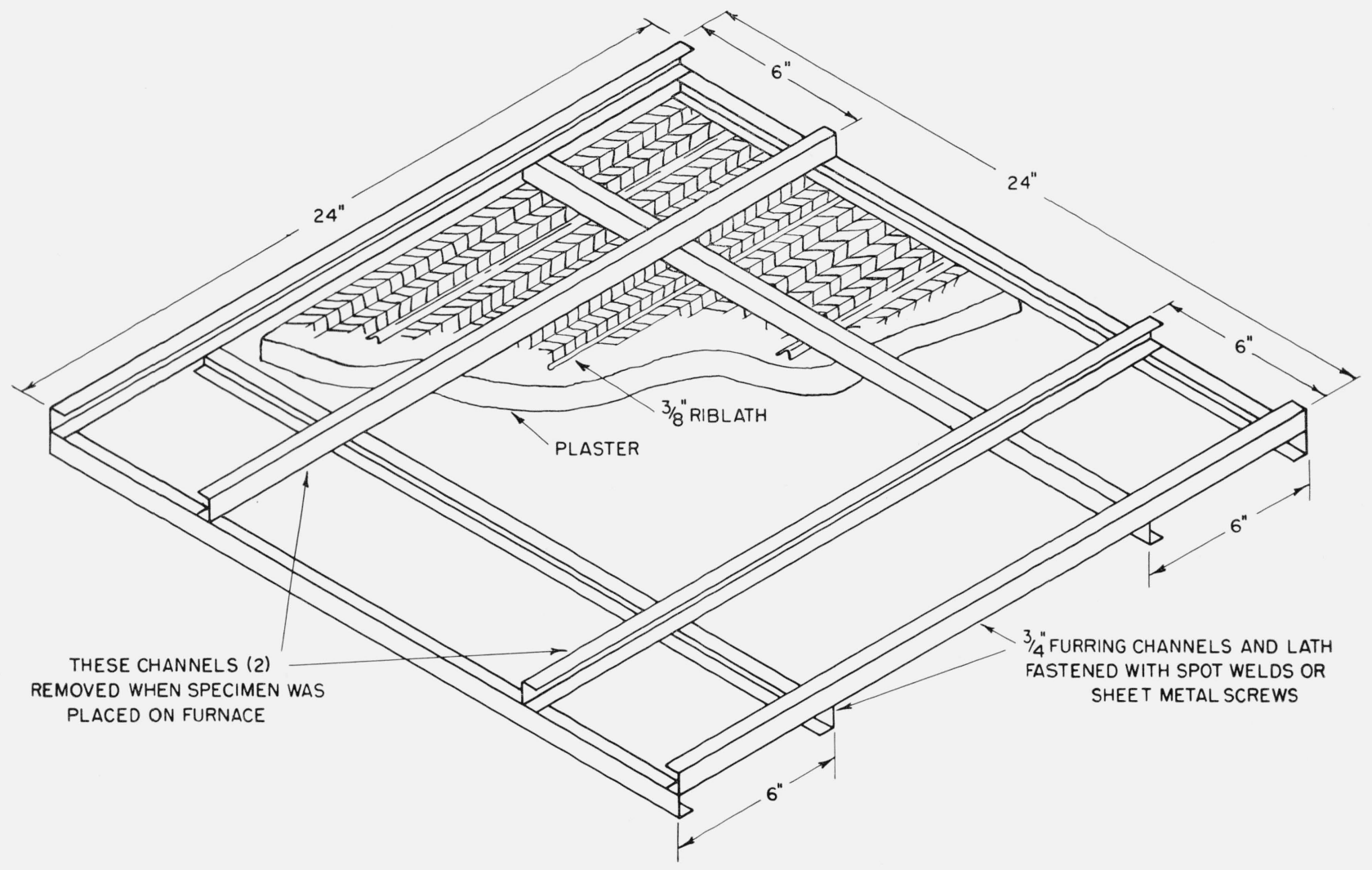

SPECIMEN AND FRAME ASSEMBLY

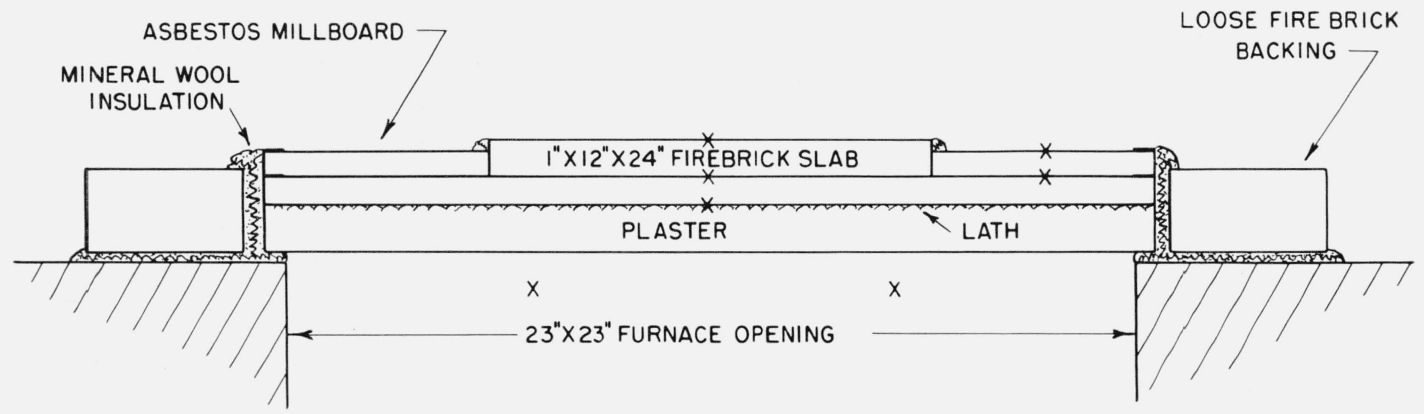

PLACEMENT OF SPECIMEN ON FURNACE

$X$ - THERMOCOUPLE LOCATIONS

Figure 2. Details of fire test specimen and placement on furnace.

were stored in intermediate relative humidity. The groups of three cubes were kept together, all in either high or intermediate relative humidity storage. The high-humidity box was operated at relative humidities from 100 to 67 percent; the intermediate humidity ranged from 58 to 26 percent. All specimens were at room temperatures (generally $72 \pm 4{ }^{\circ} \mathrm{F}$ ). The length of the aging period prior to fire tests was varied from 28 to 103 days.

\subsection{Fire Tests}

The fire tests were conducted using a small, gasfired furnace on which the specimen was laid horizontally (see fig. 3). A fire brick slab was placed over the specimen and the edges of the specimenslab assembly were insulated against lateral heat flow (see fig. 2). The arrangement of plaster specimen with fire brick slab above and a $3 / 4$-in. airspace be- 
TABLE 3. Thermal properties at $117^{\circ} \mathrm{F}\left(4^{\circ} 7^{\circ} \mathrm{C}\right)$ mean temperature

Thermal conductivities and densities measured on 8-in. square specimens; specific heats computed by formulas in reference [3]; diffusivities $\alpha=k / \rho c$. The computed $c$ and $\alpha$ values for mean only.

\begin{tabular}{|c|c|c|c|c|c|c|c|c|c|c|}
\hline $\begin{array}{l}\text { Plaster des- } \\
\text { ignation a }\end{array}$ & $\begin{array}{c}\text { Average } \\
\text { weight loss } \\
\text { in drying b }\end{array}$ & $\begin{array}{c}\text { No. of spec- } \\
\text { imens }\end{array}$ & \multicolumn{3}{|c|}{$\begin{array}{l}\text { Conductivity, } k \text {, } \\
\mathrm{Btu} / \mathrm{hr} \mathrm{ft}^{2}\left({ }^{\circ} \mathrm{F} / \mathrm{in} .\right)\end{array}$} & \multicolumn{3}{|c|}{ Density, $\rho$} & $\begin{array}{l}\text { Specific } \\
\text { heat, } c\end{array}$ & $\begin{array}{l}\text { Diffusiv- } \\
\text { ity, } \alpha\end{array}$ \\
\hline 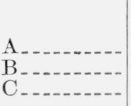 & $\begin{array}{c}\% \\
0.65 \\
.57 \\
.68\end{array}$ & $\begin{array}{l}4 \\
4 \\
4\end{array}$ & $\begin{array}{l}\text { 3. } 01 \\
\text { 2. } 35 \\
1.84\end{array}$ & $\begin{array}{l}3.16 \\
2.45 \\
1.87\end{array}$ & $\begin{array}{l}2.84 \\
2.31 \\
1.81\end{array}$ & $\begin{array}{l}l b / f t^{3} \\
94.8 \\
69.6 \\
55.2\end{array}$ & $\begin{array}{l}l b / f t^{3} \\
96.2 \\
70.9 \\
55.7\end{array}$ & $\begin{array}{l}l b / f t^{3} \\
93.4 \\
68.3 \\
54.9\end{array}$ & $\begin{array}{c}B t u / l b^{\circ} F \\
0.270 \\
.264 \\
.258\end{array}$ & $\begin{array}{c}f t^{2} / h r \\
0.0098 \\
.0106 \\
.0108\end{array}$ \\
\hline $\begin{array}{l}\text { D } \\
\text { D-L_- } \\
\text { D-H_H }\end{array}$ & $\begin{array}{l}.71 \\
.56 \\
.50\end{array}$ & $\begin{array}{l}6 \\
4 \\
4\end{array}$ & $\begin{array}{l}\text { 1. } 73 \\
\text { 1. } 80 \\
\text { 1. } 69\end{array}$ & $\begin{array}{l}1.82 \\
1.81 \\
1.73\end{array}$ & $\begin{array}{l}\text { 1. } 62 \\
\text { 1. } 78 \\
1.64\end{array}$ & $\begin{array}{l}51.0 \\
53.0 \\
51.2\end{array}$ & $\begin{array}{l}53.2 \\
54.1 \\
51.9\end{array}$ & $\begin{array}{l}49.3 \\
52.1 \\
50.5\end{array}$ & $\begin{array}{l}.256 \\
.257 \\
.252\end{array}$ & $\begin{array}{l}.0110 \\
.0110 \\
.0109\end{array}$ \\
\hline $\begin{array}{l}\mathrm{E} \\
\mathrm{E}-\mathrm{L} \\
\mathrm{E}-\mathrm{H}\end{array}$ & $\begin{array}{l}1.21 \\
1.30 \\
0.58\end{array}$ & $\begin{array}{l}2 \\
4 \\
4\end{array}$ & $\begin{array}{l}\text { 1. } 68 \\
\text { 1. } 74 \\
\text { 1. } 78\end{array}$ & $\begin{array}{l}\text { 1. } 73 \\
1.83 \\
1.85\end{array}$ & $\begin{array}{l}\text { 1. } 63 \\
1.64 \\
1.68\end{array}$ & $\begin{array}{l}52.1 \\
52.7 \\
53.9\end{array}$ & $\begin{array}{l}52.6 \\
54.4 \\
55.2\end{array}$ & $\begin{array}{l}51.6 \\
51.8 \\
52.3\end{array}$ & $\begin{array}{l}.255 \\
.258 \\
.254\end{array}$ & $\begin{array}{l}.0105 \\
.0107 \\
.0108\end{array}$ \\
\hline
\end{tabular}

a See table 2.

b Drying at $140^{\circ} \mathrm{F}$ prior to thermal conductivity determinations.

tween was designed to facilitate experimental measurements rather than to simulate a construction type.

The test procedure differed from the standard method in several respects. The plaster specimens' area exposed to fire was slightly less than $4 \mathrm{ft}^{2}$, and the specimens were neither structurally loaded nor restrained. The Standard Test Method, ASTM E-119 [2], requires that a minimum ceiling area of $180 \mathrm{ft}^{2}$ be exposed and that the floor specimen be loaded.

Also, the procedure differed from the standard in the way that the temperature of the upper surface of the fire brick slab was measured, as described in a later section.

\section{a. Furnace}

The furnace consisted of a cubical combustion chamber about $23 \mathrm{in}$. on a side and open at the top. The fuel was that from the public gas supply of Washington, D.C., and had an average heating value of 1025 to $1035 \mathrm{Btu} / \mathrm{ft}^{3}$. The gas was fed from six burners into the combustion chamber, providing diffusion flames. The flow of gas was regulated by a remotely controlled valve.

The furnace temperatures were measured by four chromel-alumel thermocouples encased in porcelain insulators and closed iron pipes. The pipes were placed so that the thermocouple junctions were approximately $2 \frac{1}{2} \mathrm{in}$. below the specimen. The gas flow was regulated automatically so that the average furnace temperatures approximated those of the standard time-temperature curve given in ASTM E-119 [2]. A metal pan that could be raised and lowered was suspended above the furnace. The pan had water supply and drain designed to permit a flow of water while maintaining an average depth of about $\frac{1}{2}$ in. This pan, with the water flowing, provided a nearly constant temperature receiver for the heat passing through the specimen. The furnace and water pan are shown in figure 3.

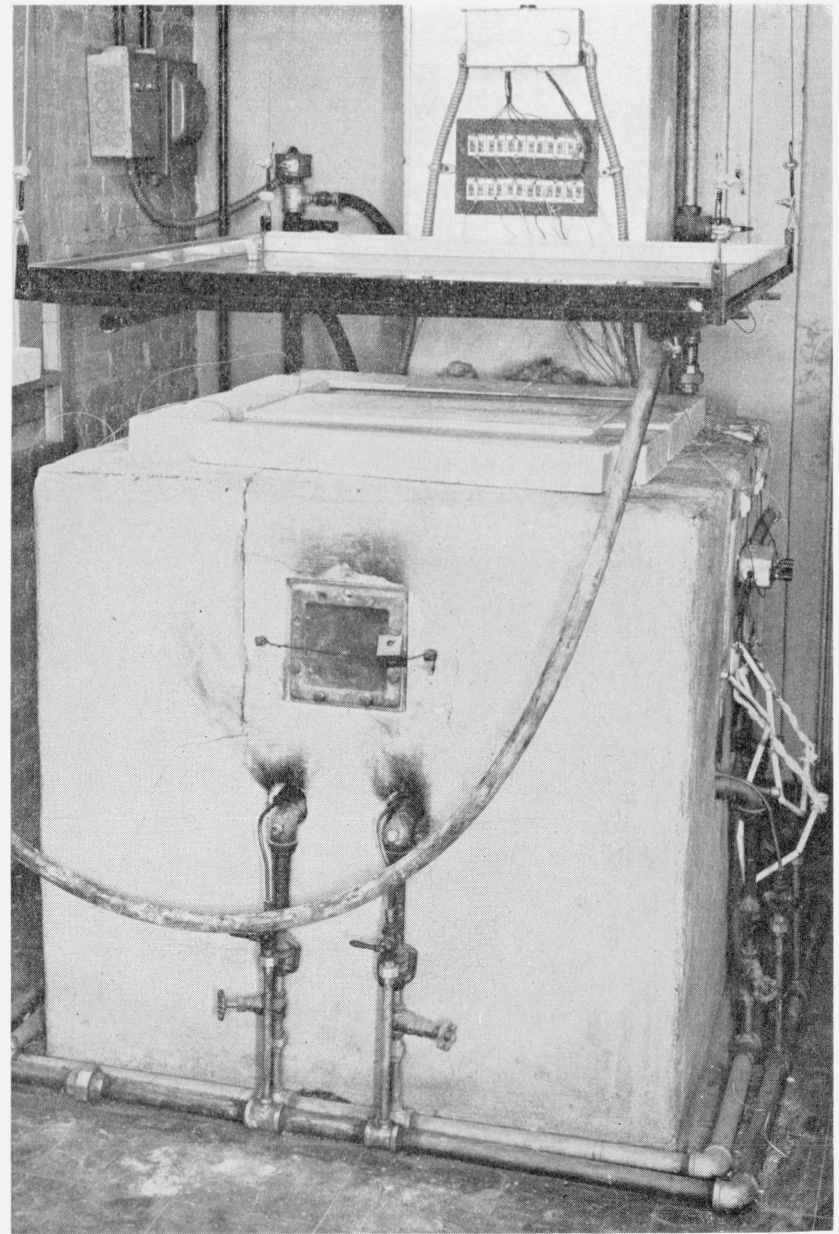

Figure 3. Furnace ready for start of a fire test. 


\section{Results}

In addition to those in the furnace, 24 gage (B\&S) chromel-alumel thermocouples were cemented on the centers of the upper surface of the plaster and upper and lower surfaces of the fire brick slab placed above the plaster, as shown in figure 2. This slab was $24 \mathrm{in}$. long, $12 \mathrm{in}$. wide, and 1 in. thick, with a density of $50.2 \mathrm{lb} / \mathrm{ft}^{3}$ A 6 -in. wide by 24 -in.-long piece of $1 / 2$-in. asbestos millboard was placed on each side of the fire brick slab to complete the cover over the specimen. Thermocouples were attached to the upper and lower surfaces of one of the pieces of millboard to permit comparison of temperatures for detection of lateral differences, if any.

The thermocouple leads were connected to selfbalancing potentiometers, and those from the furnace to automatic programing equipment for regulating the fuel supply. The program was intended to be the time-temperature curve defined in ASTM E-119. Very close agreement with this curve was achieved in the tests.

The thermocouple bead on the upper surface of the fire brick slab was partially embedded in the slab and partially exposed to air. No pad, such as used in standard floor tests, was placed over this thermocouple.

\subsection{Supplementary Tests}

Steady-state thermal conductivity determinations on the 8-in. square specimens were made in the National Bureau of Standards pentane hot-plate apparatus, at a mean plaster temperature in the range 116 to $120^{\circ} \mathrm{F}$. The specimens were dried to constant weight at $140{ }^{\circ} \mathrm{F}$ immediately prior to measurement (maximum weight loss 2.0 percent; average 0.7 percent). The data are given in table 3 .

The compressive strengths of 2 -in. cubes of the plasters were determined in a universal testing machine and are given in table 2 . The data on the aggregates are given in table 1 .

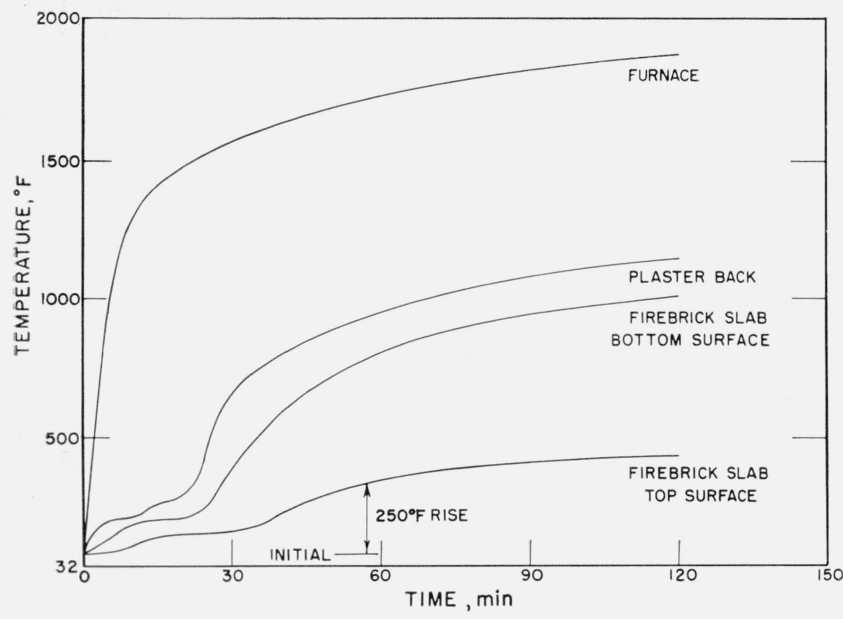

FIgure 4. Typical time-temperature curves.
The results obtained in the supplementary tests are given in tables 1,2 , and 3 . Therefore, the following comments are limited to the fire tests.

\subsection{General Behavior}

In most of the specimens, one or two transverse cracks were observed during the fire test but were not more than $1 / 32$ in. wide and therefore were judged not of great importance. These cracks became much wider as a result of cooling after the tests; however, most of the specimens were intact upon removal from the furnace. The gypsum-sand plaster specimens were exceptions. These specimens did not appear to crack more than the others during the fire exposure but did upon cooling, to the extent that sizable portions of plaster fell off some specimens during removal from the furnace.

\subsection{Data Reduction}

The performances of the various plasters in the fire tests were compared on the basis of the elapsed times at which a temperature rise of $250^{\circ} \mathrm{F}$ above the initial temperature was observed on the top surface of the fire brick slab, although the tests were continued beyond these times. Typical timetemperature curves are shown in figure 4 . The $250{ }^{\circ} \mathrm{F}$ rise is the same as that taken as a limiting criterion in standard fire-endurance tests of floors and walls, but was measured without the felted asbestos pad required in the standard test method. These temperature-rise times were plotted against plaster thickness (see figs. 5 and 6). Previous experience had indicated the fire endurances of solid specimens were a power function of thickness [4]. Therefore, the data for the plasters were subjected to least-squares analyses for fits to power functions.

The temperature-rise times for the individual specimens were then adjusted, or normalized, to a thickness of 1.0 in. by the power function. The resulting times, adjusted for thickness variations among the individual specimens, were taken as best estimates upon which to evaluate the effects of and interactions among the variables of mix, aggregate, and conditioning.

The observed temperature data and known thermal properties of the fire brick slab were used to estimate values of the apparent thermal conductivities of the plasters at elevated temperatures. Values of density were computed, knowing the densities at room temperature and the temperatures at which gypsum phase changes occur. Values of specific heat were obtained from formulas and data given by Kelley [3]. From these values of $k, \rho$, and $c$, values of the thermal diffusivity, $\alpha=k / \rho c$, were calculated.

\section{Discussion}

The results were analyzed and are discussed from the viewpoint of estimating the effects of the vari- 
ables in the program: mix, aggregate, and conditioning. There was some variation in thickness of the plaster, and in the times to the limiting $250{ }^{\circ} \mathrm{F}$ rise condition; the discussion will compare the results in terms of the mentioned variables with considerations of the dimensional and thermal characteristics that influenced the results.

\subsection{Thickness}

The techniques employed for applying plaster in this study, representative of normal building practice, lead to normal variation of thickness. Among the perlite plaster specimens for fire tests, the standard deviation was only 6.4 percent of the mean thickness. Each mean thickness was based on 25 measurements. The temperature-rise times were plotted against thickness, as shown in figures 5 and 6 . The results derived by least-squares analysis represented reasonable fits for power-function relationships between time and thickness. The exponents derived from the analyses were 1.53 for perlite plasters, 0.93 for vermiculite plasters, and 1.27 for sanded plasters. An exponent of 1.67 had been derived previously [4] from data for large-scale fire-test specimens over an appreciable range of thicknesses and a variety of building materials. Because of the fairly good agreement found with the value of 1.67 , and the much greater thickness range upon which it was based, curves based on an exponent of 1.67 were fit to the data and are shown in figures 5 and 6 ; that for the perlite plasters is repeated in figure 6 to facilitate comparisons among the plasters.

\subsection{Mixes}

Examination of the distribution of temperaturerise time versus thickness data plotted in figure 5 indicated that there was no grouping along lines according to mix within the perlite plasters. Statistical analysis of the data ${ }^{3}$ confirmed that the main effect of mix was not significant.

The results of large-scale fire tests of plaster protected building elements [4] had indicated that variation of the mix proportions of gypsum to aggregate, within the range investigated in the present study, lead to variation in the fire endurance among specimens equivalent in other details. Therefore, it appears that the effect previously observed and ascribed to mix was either (1) actually not related to mix, or (2) an interaction between mix and some other factor. Under the latter condition, several possibilities arise: (1) structural-thermal behavior of the plaster of sufficient magnitude to affect the results obtained with large "standard" specimens but not to be noticeable with specimens of the size used in this study; (2) the same possibility with

\footnotetext{
3 The temperature rise of $250^{\circ} \mathrm{F}$ used as an end point in this study is the same as
one limiting criterion in standard fire tests of walls and floors, upon which fire ratings are based, but was not measured in this study under the standard conditions. Also, no correlation has been established between small-scale tests, such as in this study, and large-scale standard fire tests. Consequently, the temperature-rise times from this study do not provide an appropriate basis for ratings or
} approvals. regard to the plaster base and support system; or (3) restraint imposed on large specimens by the test arrangement or by different structural-thermal behavior among the components of the assembly.

It was not within the scope of the present study to investigate structural behavior. However, general observations were made of the plaster during exposure and, for most specimens, only minor cracking was noted during the fire exposure.

The assumption that mix proportions made a weak contribution to an interaction effect may be further explored by consideration of the data from the tests of sanded gypsum plasters. As seen in figure 6 , these data fall significantly below those for the lightweight aggregate plasters. Although this is undoubtedly due in part to the effect of aggregate, as discussed in the next section, the sanded plasters represent a much different mix, in terms of the percent of dry gypsum by weight, than the lightweight plasters. The sanded plasters contained 20 and 33.3 percent gypsum by weight, whereas the lightweight plasters contained from 72.5 to 91.3 percent by weight. The results for 100 percent or neat gypsum plaster were similar to those of the lightweight plasters. From this it appears that the effect of mix, if any, is within the experimental scatter except for very great changes in the percentage of gypsum. It did not seem practical to check this possibility with lightweight aggregate plaster. The required volumes of perlite to produce the 20 and 33.3 percent gypsum cement by weight mixes obtained with sand would be about $40 \mathrm{ft}^{3}$ per bag of gypsum cement and $20 \mathrm{ft}^{3}$ per bag, respectively.

\subsection{Aggregate}

The study involved both variation as to type of aggregate and variation of density range within one type.

\section{a. Variation as to Type}

Examination of figure 6 indicates that the differences of temperature-rise times between the perlite and vermiculite plasters were small, whereas that between either of them and the sanded plasters was comparatively large. Statistical analyses were used to evaluate the apparent differences.

The average time normalized to 1.0 -in. thickness for the vermiculite plasters aged in intermediate relative humidity was $61.1 \mathrm{~min}$, whereas the corresponding time for the equivalent perlite plaster specimens was $58.4 \mathrm{~min}$, a difference of $2.7 \mathrm{~min}$. However, statistical analysis ( $t$-test) indicated that the difference of $2.7 \mathrm{~min}$ was not significantly different from zero, since the 95 percent confidence limits on the difference were -1.7 to $+7.1 \mathrm{~min}$. Therefore, it is possible to say with considerable assurance that these experiments showed no real difference between plasters of the two lightweight aggregates.

The average normalized time for the sanded plasters was $39.5 \mathrm{~min}, 21.6 \mathrm{~min}$ less than that for the vermiculite plasters. The same statistical test 


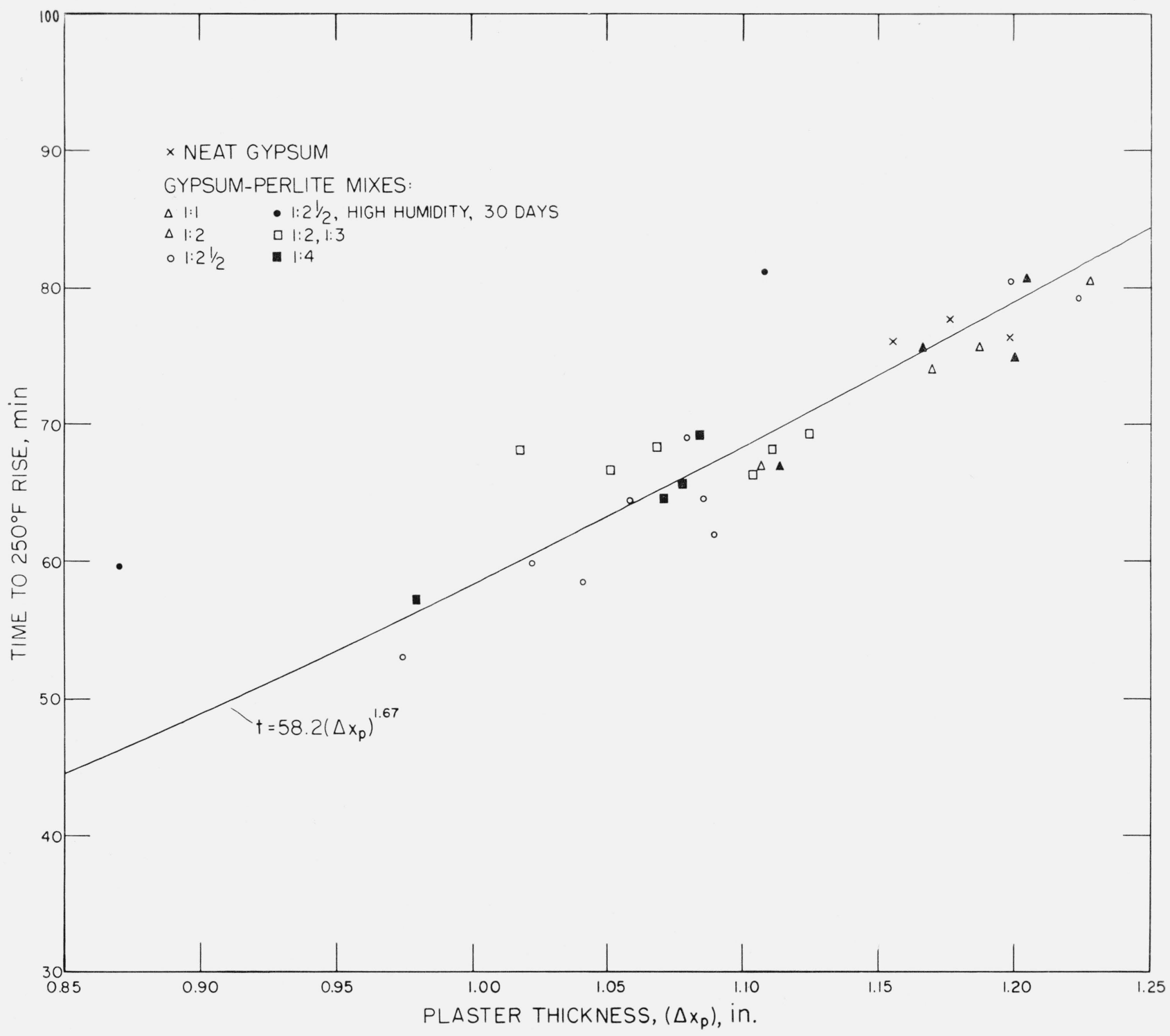

Figure 5. Time to $250^{\circ} \mathrm{F}$ rise versus thickness of perlite plaster specimens, with curve $\mathrm{t}=58.2\left(\triangle \mathrm{x}_{\mathrm{p}}\right)^{1.67}$.

mentioned above was applied to this difference and indicated the confidence limits were from 18.8 to $24.4 \mathrm{~min}$. Therefore the difference in fire endurances between sanded and lightweight aggregate plasters indicated in figure 6 is shown real.

\section{b. Variation of Perlite Density}

Two-coat specimens of 1:2, 1:3 mix and one-coat specimens of $1: 2 \frac{1}{2}$ mix were made with perlites of each of the three densities The average times from two specimens of each perlite density for $1: 2,1: 3$ mix were $62.2,63.3$, and $66.0 \mathrm{~min}$, respectively, for high, intermediate, and low density; for the $1: 2 \frac{1}{2}$ mix (five specimens of intermediate and two each of high and low density), the corresponding average times were 57.7, 63.3, and $59.1 \mathrm{~min}$. The actual differences were small and statistical analyses indi- cated that they were of doubtful significance. Existing standards (ASTM C-35) place limits on the allowable density range of perlite plaster aggregate at 7.5 to $15 \mathrm{lb} / \mathrm{ft}^{3}$. Although the perlites used in this study had densities between 7.9 and $12.9 \mathrm{lb} / \mathrm{ft}^{3}$, it is doubtful that statistically significant differences would have been found had the full range been explored.

\subsection{Aging Conditions}

The specimens were aged for periods of from 28 to 103 days and in ambients of various relative humidities. It had been intended that specimens should be aged at relative humidities of about 50 percent or over 90 percent. However, due to mechanical difficulties, the specimens fell into three 


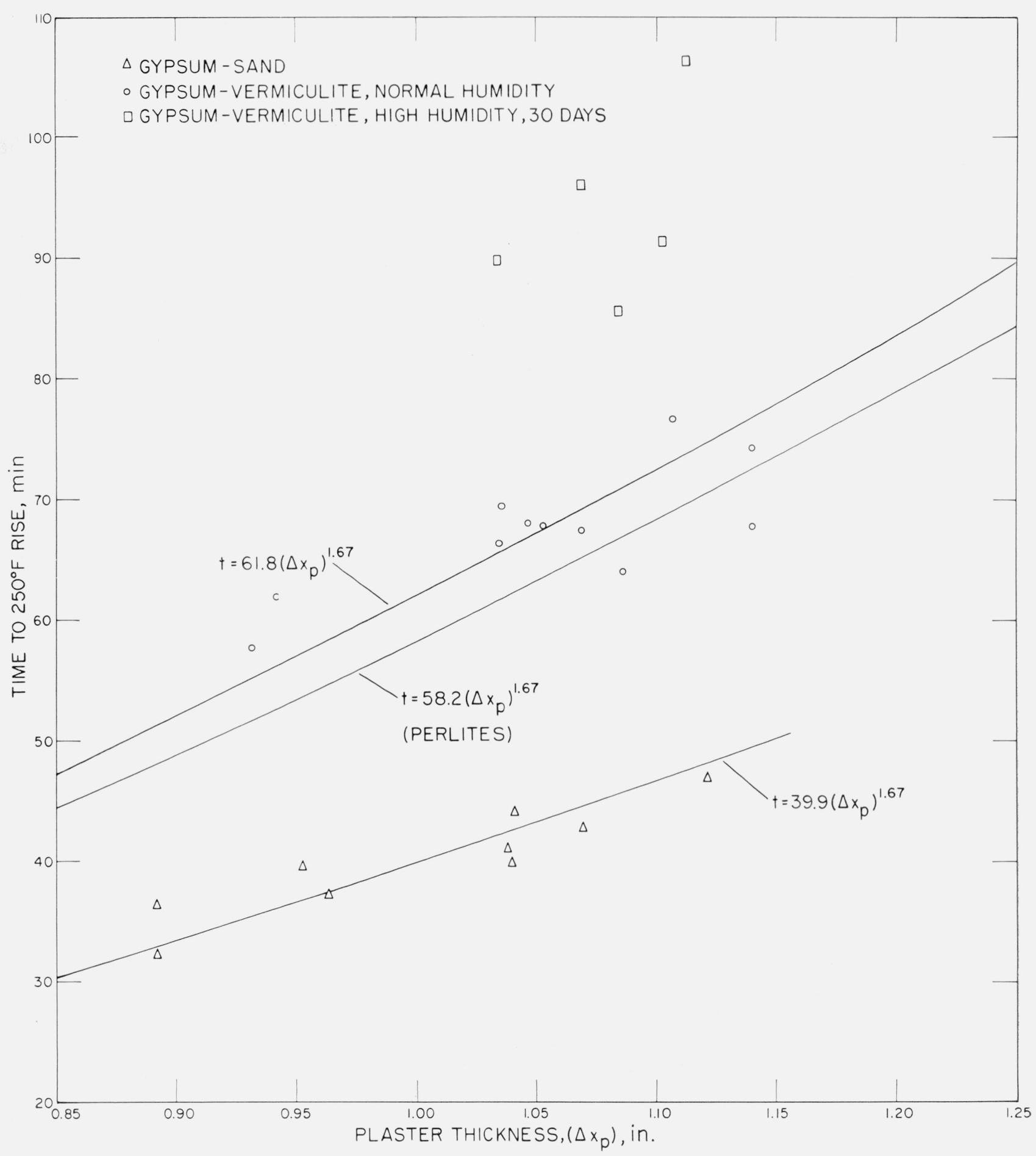

FiguRE 6. Time to $250^{\circ} \mathrm{F}$ rise versus thickness of vermiculite and sand aggregate plasters.

The curve fitted for perlite plasters in figure 5 is shown for comparison. 
groups in terms of humidity conditioning: (1) those kept at over 85 percent; (2) those started at over 90 percent but falling to about 70 percent; and (3) those kept in the range 25 to 60 percent.

All the specimens were kept at high relative humidity until removed from the forms at an age of one day. The ambient temperature of all the aging chambers was kept at $72 \pm 4^{\circ} \mathrm{F}$.

\section{a. Effect of Relative Humidity of Ambient}

Due to the variation of the relative humidity of the ambient during the aging of some specimens, it was decided to compare the results for the specimens on the basis of the mean relative humidity during the final 7 days of conditioning. For the perlite plasters, the average time for 20 specimens at 51 percent average relative humidity was $58.4 \mathrm{~min}$; for 8 specimens at 82 percent, $59.2 \mathrm{~min}$; and for 2 specimens at 95 percent, $71.6 \mathrm{~min}$. This would correspond to very slight increase in time with increase in relative humidity except at very high values of the latter, as illustrated in figure 7 . It would be expected that high relative humidity of the ambient would lead to increased moisture content for most materials, and increased time to reach a temperature-rise end-point in a fire test. It appears evident from the results that such increase, if actually significant, is small for perlite plasters, except at high relative humidities.

For the vermiculite plasters, the results were only slightly different: the average time for 5 specimens at an average relative humidity of 45 percent was $61.1 \mathrm{~min}$; that for 3 specimens at 78 percent was $62.1 \mathrm{~min}$; and that for 5 specimens at 95 percent was $83.3 \mathrm{~min}$. The increase at very high humidity was appreciably greater than that for perlite plasters,

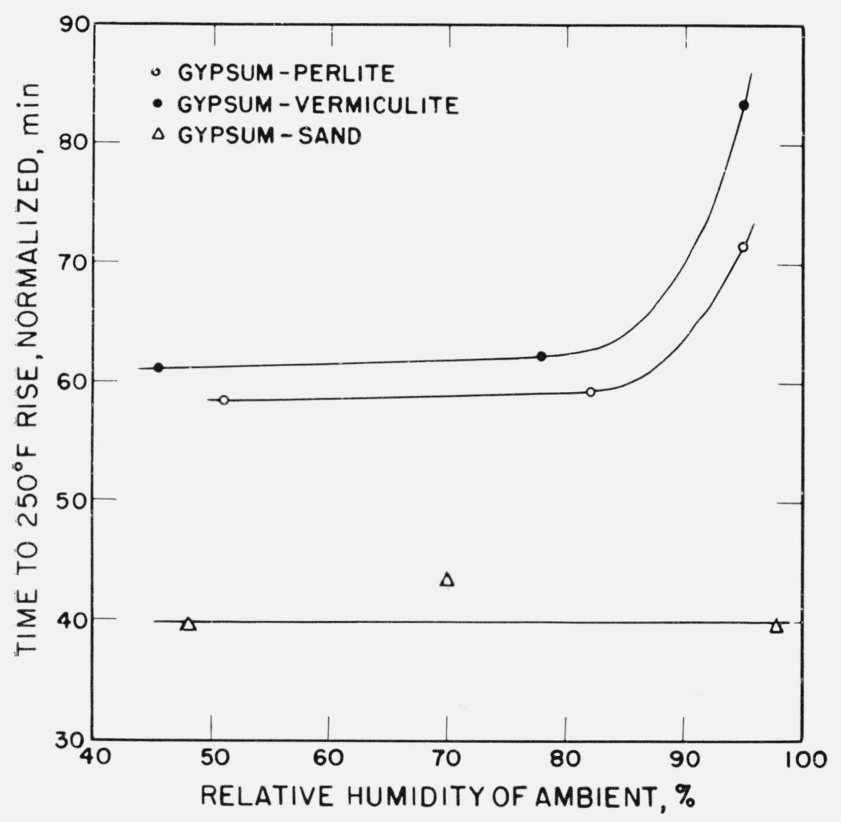

Figure 7. Time to $250^{\circ} \mathrm{F}$ rise versus relative humidity of ambient. as illustrated in figure 7 . Since the perlite plasters conditioned at 95 percent relative humidity were all of the same mix as the vermiculite plasters, mix does not enter into the comparison. The duration of aging, which is discussed later in this paper, may have had some influence, but does not fully account for the above time differences.

The times for both perlite and vermiculite plasters were not affected appreciably by variation of relative humidity of the ambient except above 90 percent. There was no evidence of sensitivity of the sanded plaster specimens to variation in relative humidity of the ambient.

\section{b. Duration}

The majority of the perlite specimens, about half of the vermiculite specimens, and half the sand specimens were aged for approximately 12 weeks; the remainder were aged approximately 30 days. Among the specimens aged at normal humidities, the results for those aged 30 days were comparable to those aged 12 weeks for each aggregate. However, among the specimens aged at high humidities, the times for the perlite plasters aged 30 days were appreciably longer than for those aged 12 weeks; for the vermiculite plasters the times were also appreciably longer. The results that would have been obtained with specimens aged only a few days might have been significantly different, but such short durations were not considered of practical importance.

The foregoing interactions between aging periods, at various humidities, and times observed in the fire tests might be somewhat different for much thicker or much thinner plaster applications, or for those not exposed to fairly free air circulation at both faces. The 1-in. plaster thickness approached in the specimens was believed to be a representative choice within the range of thicknesses normally applied to metal lath. Vapor barriers in close proximity to the back surface of plaster are not found in the majority of uninsulated walls, partitions, or ceilings.

\subsection{Thermal Properties}

The thermal properties that are of interest in any given heat-flow situation are influenced by the nature of the heat flow, whether transient or steady-state. The fire exposure employed in this study, and in standard fire-endurance tests, is an example of transient heat-flow phenomena that tends toward steady state as elapsed time increases. With gypsum plaster, the heat flow during the early stages of a test is complicated by latent heat losses to evaporation of free water in the aggregate, change-of-state or calcination of the gypsum, and evaporation of the water of crystallization liberated during the calcination. These built-in heat sinks account for the irregular shapes of the temperature curves in figure 4 during the first $40 \mathrm{~min}$, and for a large part of the value of gypsum as a fire protection material.

Since both transient heat flow and an approximation of steady-state heat flow occurred during the fire tests, both thermal conductivity, $k$, and thermal 
diffusivity, $\alpha$, were of interest. The steady-state thermal conductivity values of the individual plaster specimens, as determined in the NBS pentane hotplate and summarized in table 3 , were compared with the temperature-rise times from the fire tests. It was observed that specimens exhibiting longer times in the fire tests corresponded to plasters having lower thermal conductivity values.

Mean values of $\alpha$, and the values of $k, \rho$, and $c$ from which $\alpha$ was computed, are given in table 3 . Values of $k$ and $\rho$, density, were determined from the 8-in. square specimens; values of $c$, specific heat, were computed from recognized formulas [3] solved using the temperature at which $k$ was measured. The temperature-rise times were analyzed, by leastsquares method, for a relationship with $\alpha$. It was found that the specimens exhibiting longer times corresponded to lower values of diffusivity.

It was of interest to observe the interdependence of density and thermal conductivity, from the data on both measured on the 8-in. square specimens. A plot of $k$ versus $\rho$ for the plasters of all mixes and aggregates is given in figure 8 . The data fall into groups corresponding to the different mixes. The density variations among the mixes of $1: 2 ; 1: 2$,
$1: 3$; and $1: 2 \frac{1}{2}$ for lightweight aggregates were so small that the data for these three similar mixes blended into a single large group. The two lines, one for the sanded plasters and the other for lightweight aggregate plasters, intersect very near the group of data for neat gypsum plaster. This was expected, since each line represents a range of solid dilution of gypsum: the one, dilution with material of lower density and the other, dilution with material of a higher density.

A similar plot of $\alpha$ versus $\rho$ showed a greater scatter than that of $k$ versus $\rho$ as percentages of the overall ranges of $k$ and $\rho$. However, the data again fell into groupings by mix and reasonable fits were obtained with straight lines. The intersection of the lines fell moderately near the group for neat gypsum. The greater scatter probably reflects uncertainties in the chemical compositions of the mixtures and therefore in the computed values of specific heat, plus the observational and round-off errors in the values of $k$ and $\rho$.

For the sanded gypsum plasters, both $k$ and $\alpha$ increased with increased density. However, for the lightweight aggregate plasters, $k$ increased and $\alpha$ decreased with increased density. This agrees

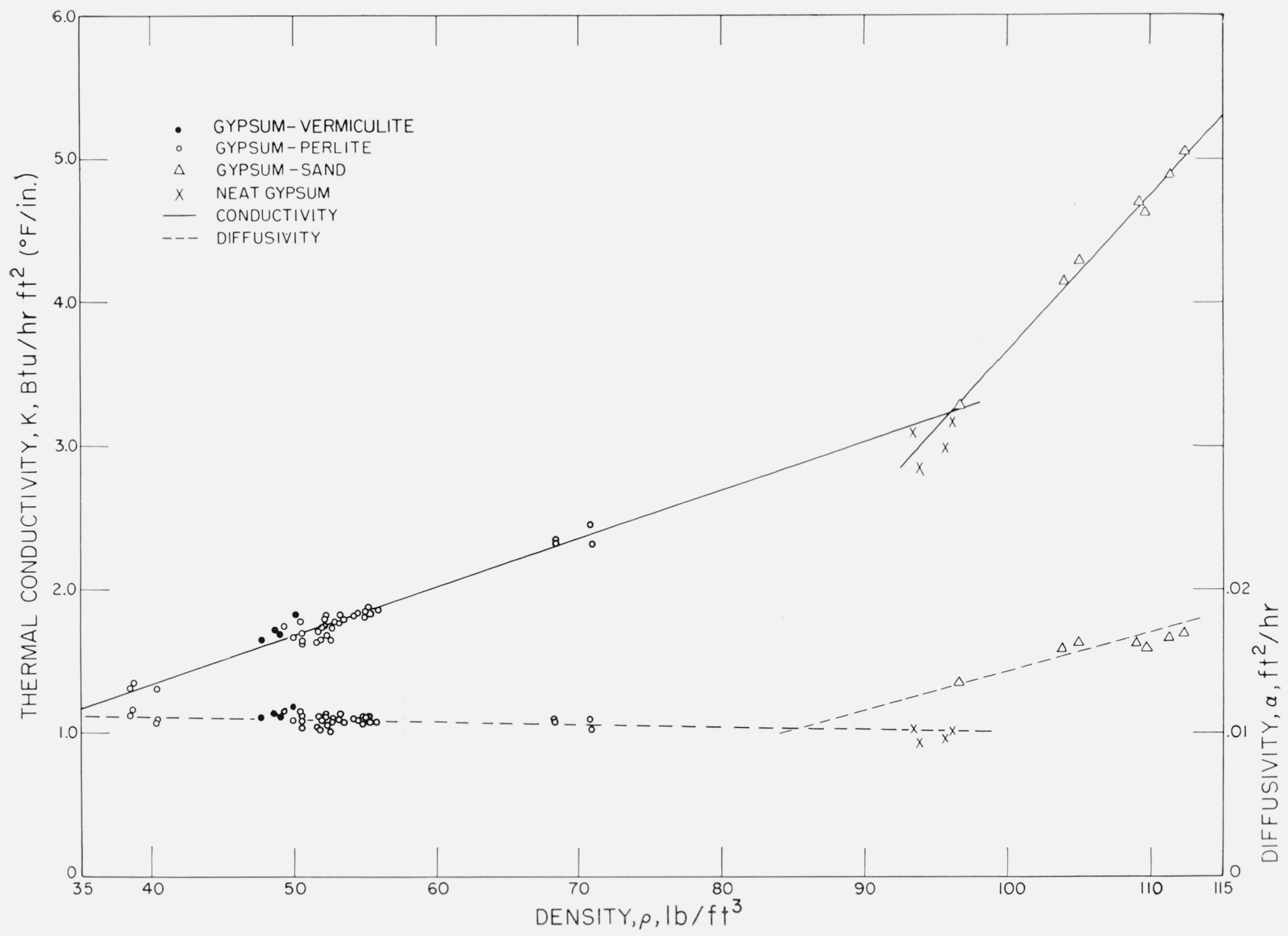

FIGURe 8. Thermal conductivity and thermal diffusivity versus density, at $11 \gamma^{\circ} \mathrm{F}$. 
with previously obtained data for concretes over a wide range of densities, which showed $k$ increasing over the entire range but $\alpha$ decreasing at lower densities and then increasing at higher densities.

The data for the concretes did not fit linear functions of density. Although the plaster data for $k$ versus $\rho$ were obtained under conditions that give considerable confidence in the linear function fit, the computed values of $c$ that entered in to the values of $\alpha$ lead to uncertainty in the latter. Therefore, the straight lines drawn in the figure should be recognized as merely illustrating the general trend. The true function expressing the $\alpha$ versus $\rho$ relationship for these plasters may be other than linear in form.

\subsection{Elevated Temperature Estimates of Thermal Properties}

Values of density at elevated temperatures were calculated from the densities measured at room temperature and the known changes in gypsum; values of specific heat were calculated by means of the same formulas mentioned in the preceding section. The accuracy of results obtained by such procedures depends on how well the initial composition of the plaster is known, and on the assumptions made as to the changes that take place under the influence of increased temperature.

Determinations of steady-state thermal conductivity at elevated temperatures were made on a specimen from the fire brick slab [5]. Similar determinations could not be made on the plaster specimens. However, the temperature data from the fire tests and the experimentally determined values of $k$ for the fire brick slab were used to obtain estimates of the apparent thermal conductivities of the plasters at elevated temperatures. The changes of temperature with time became essentially constant in the later stages of the fire tests; the differences in temperature across the plaster, air space, and fire brick slab all tended toward constant values as shown in figure 9. Although steady-state conditions were not reached, a quasi-steady state was approached.

In the calculation of apparent conductivity, it was assumed that the temperature of the exposed plaster surface was equal to that indicated by the encased furnace thermocouples. This assumption was based on data from two fire tests of plaster specimens with fine wire thermocouple junctions on the surface. Computations made using these data showed that, during quasi-steady state, the average error introduced by this assumption was less than one percent of the apparent thermal conductivity value, and the maximum error was less than two percent.

The derivation of the formula by which the apparent thermal conductivity values were computed began with consideration of steady-state one-dimensional heat flow through two slabs (see fig. 10), which may be expressed by the following heat- balance equation :

$$
Q=k_{p} \frac{\partial T_{p}}{\partial x}=k_{s} \frac{\partial T_{s}}{\partial x}
$$

where $Q$ is heat-flow rate, $k$ is thermal conductivity, $\partial T / \partial x$ is temperature gradient, and subscripts $p$ and $s$ refer to plaster and fire brick slab, respectively. Solving (1) for $k_{p}$, we get:

$$
k_{p}=k_{s} \frac{\partial T_{s}}{\partial x} / \frac{\partial T_{p}}{\partial x}
$$

Since $k$ varies with temperature, neither it nor temperature gradient is exactly constant through a slab having different temperatures at the two surfaces, even at steady state. Therefore, eq (2) implies mean values or knowledge of the values of $k$ and the temperature gradients at the surfaces $x_{1}$ and $x_{2}$. However, steady-state gradients through solid slabs are ordinarily taken as the temperature difference between faces divided by slab thickness, so eq (2) becomes:

$$
k_{p}^{\prime}=k_{s} \frac{T_{2}-T_{3}}{\Delta x_{s}} \cdot \frac{\Delta x_{p}}{T_{0}-T_{1}} .
$$

This equation is based on no heat loss or gain in either slab-fire brick or plaster-whereas some heat was being absorbed in each. Therefore, the temperature gradients in the slabs were not linear functions of the $x$ dimension. However, at some plane within each, the gradient must have been equal to the values given by the ratios in (3). It was assumed that this was the midplane of each, and that the heat flow at $\bar{x}_{p}$, the midplane of the plaster, was equal to that at $\bar{x}_{s}$, the midplane of the fire brick slab, plus the rate at which heat was absorbed in heating the shaded portions in figure 10. From these assumptions, the following was derived:

$k_{p}=k_{s} \frac{\partial T_{s}}{\partial x} / \frac{\partial T_{p}}{\partial x}+\left(1 / \frac{\partial T_{p}}{\partial x}\right)\left[\frac{\Delta x_{p}}{2} \rho_{p} c_{p} \frac{\partial T_{p}}{\partial t}+\frac{\Delta x_{s}}{2} \rho_{s} c_{s} \frac{\partial T_{s}}{\partial t}\right]$

where all the temperature gradients with respect to thickness and with respect to time are at $\bar{x}_{p}$ or $\bar{x}_{s}$. Substituting approximations for the partial derivatives gives:

$$
\begin{array}{r}
k_{p}^{\prime \prime}=k_{s} \frac{T_{2}-T_{3}}{x_{3}-x_{2}} \cdot \frac{x_{1}-x_{0}}{T_{0}-T_{1}}+\frac{x_{1}-x_{0}}{T_{0}-T_{1}}\left\{\rho_{p} c_{p} \frac{\left(x_{1}-x_{0}\right)}{2}\right. \\
{\left[\frac{\left(T_{0}+T_{1}\right)_{t+\Delta t}-\left(T_{0}+T_{1}\right)_{t}}{2 \Delta t}\right]+\rho_{s} c_{s} \frac{\left(x_{3}-x_{2}\right)}{2}} \\
\left.\left[\frac{\left(T_{2}+T_{3}\right)_{t+\Delta t}-\left(T_{2}+T_{3}\right)_{t}}{2 \Delta t}\right]\right\}
\end{array}
$$

where $t$ is time, $\frac{x_{1}-x_{0}}{2}=x_{1}-\bar{x}_{p}, \frac{x_{3}-x_{2}}{2}=\bar{x}_{s}-x_{2}$, and the other symbols are as previously used. The prime and double prime are used with $k_{p}$ in eqs (3) and (4), as 
well as in table 4 and the subsequent discussion, to emphasize that the formulas, when used with the data from the fire tests, gave values of "apparent" thermal conductivity, obtained under quasi-steadystate conditions.

It is of interest to note that the portion of eq (4) to the left of the first plus sign is identical to eq (3); the remainder of eq (4) being a correction for deviation from steady state. Strictly, the major brackets in (4) should include a correction factor for heating the air between the slabs. In fact, sample calculations indicated the correction for air would be of the order of one-fortieth of one percent of $k_{p}^{\prime \prime}$. 'This would not show in the numerical values in table 4 unless they were given to two additional figures. Also, a correction should be made for edge effects. However, examination of the temperature data for the bottom face of the fire brick slab with that for the bottom face of the asbestos board (see fig. 2) showed small temperature differences and, therefore, small edge effects due to lateral heat flow.

Values of $k_{p}^{\prime \prime}$ were computed from data for neat plaster, gypsum-perlite and gypsum-vermiculite plasters at $1: 2 \frac{1}{2} \mathrm{mix}$ and gypsum-sand plaster at $1: 2 \mathrm{mix}$. The values were plotted against mean plaster temperature and curves faired through them, except for the sanded plaster. The latter indicated $k_{p}^{\prime \prime}$ of the order 3 to 5 but were too widely scattered to be a satisfactory basis for a curve. This result is not surprising in view of the comparatively short

TABLE 4. Apparent and computed values of thermal properties at elevated temperatures

Apparent conductivity $k^{\prime \prime}$ determined from data; specific heat computed from formulas; density based on measured density at room temperature; apparent diffusivity $\alpha^{\prime}$ computed by $\alpha^{\prime}=k^{\prime \prime} / \rho c$.

\begin{tabular}{l|l|l|l|l}
\hline \hline \multirow{2}{*}{ Specimen } & \multicolumn{3}{|c}{ Temperature } \\
\cline { 2 - 4 } & $1,200^{\circ} \mathrm{F}$ & $1,300^{\circ} \mathrm{F}$ & $1,400{ }^{\circ} \mathrm{F}$ & $1,500^{\circ} \mathrm{F}$ \\
\hline
\end{tabular}

A pparent conductivity, $k^{\prime \prime}, \mathrm{Btu} / \mathrm{hr} \mathrm{ft}^{2}\left({ }^{\circ} \mathrm{F} / \mathrm{in}.\right)$

\begin{tabular}{l|l|l|l|l}
\hline Neat gypsum & 2.00 & 2.20 & 2.35 & 2.50 \\
Gypsum-perlite, $1: 21 / 2$ & 1.00 & 1.55 & 1.60 & 1.75 \\
Gypsum-vermiculite, $1: 21 / 2$ & 1.65 & 1.65 & 1.70 & 1.70 \\
Gypsum-sand, $1: 2 \ldots$ & & & \\
\hline
\end{tabular}

Specific heat, $c, B t u / l b^{\circ} \mathrm{F}$

\begin{tabular}{|c|c|c|c|c|}
\hline $\begin{array}{l}\text { Neat gypsum } \\
\text { Gypsum-perlite, } 1: 21 / 2 \\
\text { Gypsum-vermiculite, } 1: 21 / 2 \\
\text { Gypsum-sand, } 1: 2\end{array}$ & $\begin{array}{r}0.283 \\
.281 \\
.281 \\
.299\end{array}$ & $\begin{array}{r}0.292 \\
.290 \\
.290 \\
.308\end{array}$ & $\begin{array}{r}0.302 \\
.298 \\
.298 \\
.317\end{array}$ & $\begin{array}{r}0.312 \\
.306 \\
.306 \\
.325\end{array}$ \\
\hline
\end{tabular}

\begin{tabular}{|c|c|c|c|c|}
\hline \multicolumn{5}{|c|}{ Density, $\rho, l b / f t^{3}$} \\
\hline $\begin{array}{l}\text { Neat gypsum } \\
\text { Gypsum-perlite, } 1: 21 / 2 \\
\text { Gypsum-vermiculite, } 1: 21 / 2 \\
\text { Gypsum-sand, } 1: 2\end{array}$ & $\begin{array}{r}75.0 \\
42.2 \\
39.9 \\
102.0\end{array}$ & $\begin{array}{r}75.0 \\
42.2 \\
39.9 \\
102.0\end{array}$ & $\begin{array}{r}75.0 \\
42.2 \\
39.9 \\
102.0\end{array}$ & $\begin{array}{r}75.0 \\
42.2 \\
39.9 \\
102.0\end{array}$ \\
\hline
\end{tabular}

Apparent diffusivity, $\alpha^{\prime}, f t^{2} / h r$

\begin{tabular}{|c|c|c|c|c|}
\hline $\begin{array}{l}\text { Neat gypsum } \\
\text { Gypsum-perlite, } 1: 21 / 2 \\
\text { Gypsum-vermiculite, } 1: 21 / 2 \\
\text { Gypsum-sand, } 1: 2\end{array}$ & $\begin{array}{l}0.0080 \\
.0106 \\
.0122 \\
(a)\end{array}$ & $\begin{array}{r}0.0083 \\
.0105 \\
.0120\end{array}$ & $\begin{array}{r}0.0086 \\
.0107 \\
.0118\end{array}$ & $\begin{array}{r}0.0090 \\
.0112 \\
.0117\end{array}$ \\
\hline
\end{tabular}

a Data gave $k^{\prime \prime}$ values in range 3 to 5 but widely scattered; therefore they were not tabulated, nor used to compute $\alpha^{\prime}$.

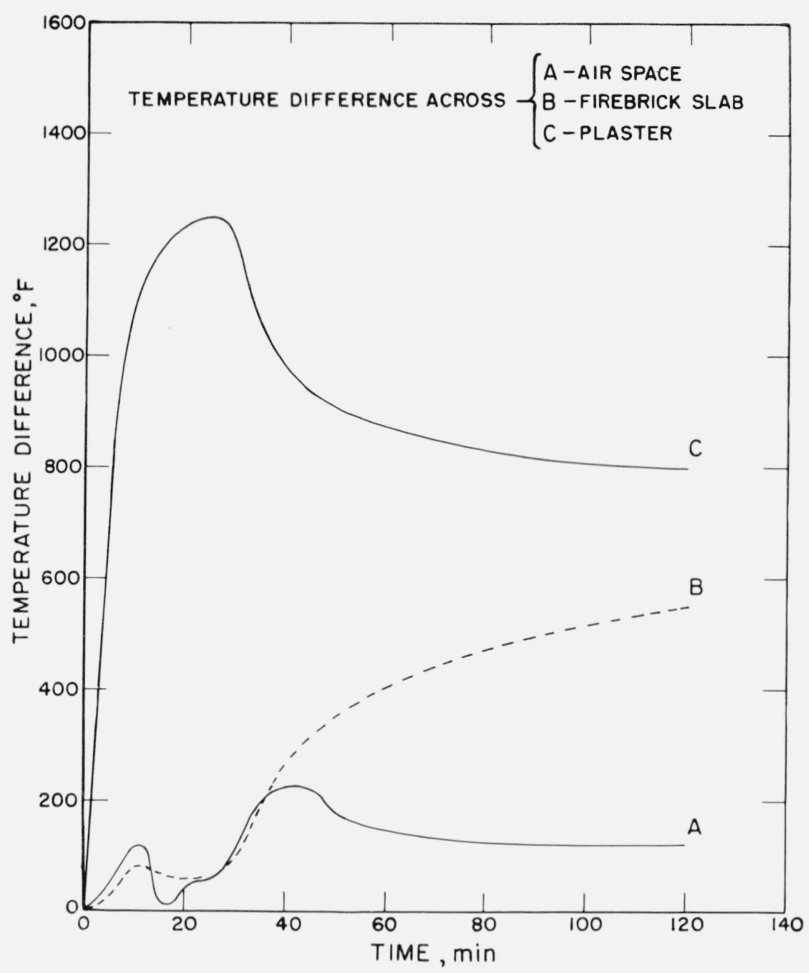

Figure 9. Curves of typical temperature differences during fire test.

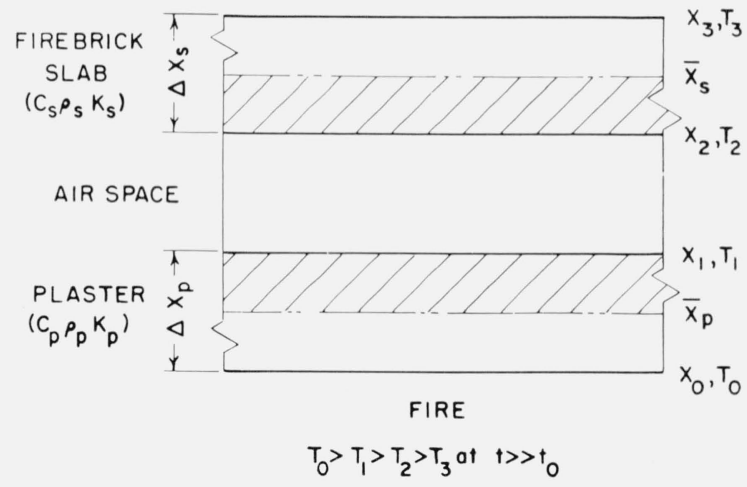

Figure 10. Physical arrangement.

durations of the tests with gypsum-sand plasters, in which even quasi-steady state was not approached.

The curves obtained are shown in figure 11. The data for gypsum-perlite and gypsum-vermiculite were so intimately associated that the latter were omitted in order to avoid unduly reducing the clarity of the figure. The scatter of the omitted gypsum-vermiculite points was similar to that of those for gypsum-perlite. Table 4 gives values of $k_{p}^{\prime \prime}$ taken from the curves, along with computed values of $c, \rho$, and $\alpha^{\prime}$.

As a check on the values obtained by using eq (4), two gypsum-perlite plaster specimens of $1: 2 \frac{1}{2}$ mix 


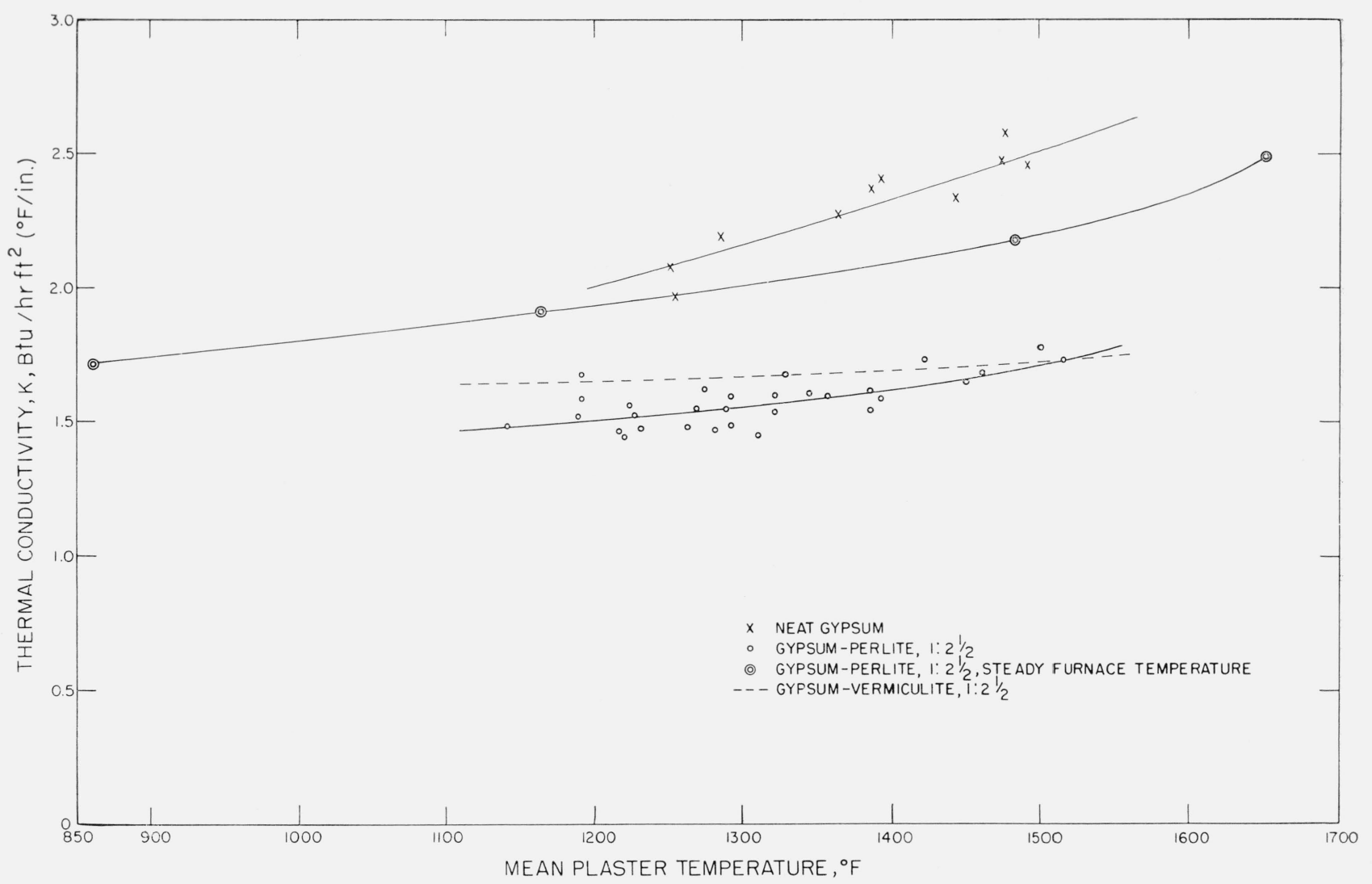

FiguRE 11. Apparent thermal conductivities at elevated temperatures.

were tested with the same instrumentation employed throughout the study, but with the furnace programed for constant temperatures. Data were obtained at four temperatures, under steady-state conditions, and are shown in figure 11. The curve through these is significantly above, but of the same shape as that for the data from eq (4). Two factors undoubtedly contribute to this discrepancy between $k_{p}^{\prime \prime}$ and $k_{p}$. First, in eqs (3) and (4) there is the product $\frac{T_{2}-T_{3}}{x_{3}-x_{2}} \cdot \frac{x_{1}-x_{0}}{T_{0}-T_{1}}$. The coefficients of thermal expansion for plasters are so small that values of the $x$ 's are essentially constant but, as shown in figure 9 , $T_{2}-T_{3}$ (curve B) approaches steady state from lower values and $T_{0}-T_{1}$ (curve C) approaches from higher values. Therefore, the ratio $\frac{T_{2}-T_{3}}{T_{0}-T_{1}}$ would be expected to remain below corresponding steady state values throughout fire tests, resulting in low values of $k_{p}^{\prime \prime}$. Secondly, the values of

$$
\frac{\left(T_{0}+T_{1}\right)_{t+\Delta t}-\left(T_{0}+T_{1}\right)_{t}}{2 \Delta t}
$$

and of

$$
\frac{\left(T_{2}+T_{3}\right)_{t+\Delta t}-\left(T_{2}+T_{3}\right)_{t}}{2 \Delta t}
$$

were used to approximate values of $\partial T / \partial t$ at the mid- planes of the plaster and firebrick slabs. Although it was assumed that the midplane gradients were equal to the overall gradients, the midplane temperatures would be less than the average of the suriface temperatures. The difference between actual and approximated midplane temperatures would diminish as time increased, and steady state was more nearly approached, so the rate of increase of the midplane temperature would be greater than the mean rate of increase of the two surface temperatures. Therefore, the correction terms in eq (4) for both the plaster and the slab should be expected to be low. However, the agreement between the two curves for gypsumperlite plasters in figure 11, both in shape and order of magnitude, were such as to give some confidence in the use of eq (4).

Several important points must be stressed in connection with the estimates. First, they are at best only estimates. Second, they include the effects of cracks and all the other changes in the plaster resulting from fire exposure. It is because of the tendency of gypsum plaster to crack when heated to elevated temperatures that thermal conductivity at high temperatures could not be measured by laboratory equipment and techniques used to obtain the values in table 3 . However, the fact that the values in table 4 include the effect of cracks is considered an advantage because the values are, therefore, more closely related to the behavior of gypsum plaster as a fire-protection material. 
A third important point is in regard to extrapolation of the curves in figure 11. No extrapolation to lower temperatures should be attempted to obtain values for fire-exposure or other non-steady-state computations since the effects of moisture evaporation and migration will be important at lower mean plaster temperatures. However, limited extrapolation to lower temperatures might be acceptable to obtain values for steady-state computations. Consideration of plaster thickness is a fourth point. For thicknesses much less than those involved in this study, e.g., $1 / 2$ in., the effects of moisture would be eliminated more rapidly, corresponding to lower plaster mean temperatures. In this case, some relaxation of the above prohibition against extrapolation to lower temperatures might be permissible. Conversely, at thicknesses of $1 \frac{1 / 2}{i n}$. or greater, the effects of moisture might not be eliminated until mean plaster temperatures exceed $1,200^{\circ} \mathrm{F}$.

It is worth noting that, for plasters of the same mixes, the values of $k_{p}$ given in table 3 , for $117{ }^{\circ} \mathrm{F}$, are higher than those given for $1,200{ }^{\circ} \mathrm{F}$ in table 4 , although the latter and figure 11 both indicate higher $k_{n}$ at increased temperatures. This points up the significant effect of the loss of chemically combined and other moisture on $k_{p}$. This fact is very desirable from the fire-protection viewpoint, but complicates the problem of predicting fire endurance, or any heatflow solution involving the calcination of gypsum, by computational or analytical means.

\section{Summary}

This study was designed to examine the effects of mix, aggregate, and conditioning on the fire endurances, in terms of a limiting temperature rise, of gypsum plasters. It was not intended to examine the effects of large variation of thickness, nor was it felt that such was needed because of the published data from many standard fire tests and conclusions based thereon.

Under the conditions of specimen size and test conditions employed, the study showed that the mix ratio of gypsum to aggregate has little, if any, influence on the time to a $250^{\circ} \mathrm{F}$ temperature rise, for a single aggregate within the range of mixes ordinarily employed. The perlite and vermiculite aggregate plasters exhibited signiiicantly longer temperature-rise times than did the sanded gypsum plasters. This was attributed in part to the differences between the aggregates and in part to the fact that the conventional mixes for sanded plasters correspond to quite different ranges of gypsum-toaggregate ratios on a weight basis. Variation of the density of perlite aggregate over a range of about 8 to $13 \mathrm{lb} / \mathrm{ft}^{3}$ had no signiincant influence on the limiting temperature-rise time.

The effect of aging or conditioning was pronounced for the combination of very high relative humidity atmospheres and relatively short periods of aging. For perlite and vermiculite aggregate plaster specimens conditioned 30 days in atmospheres at relative humidities near 95 percent and temperatures near 70 to $75^{\circ} \mathrm{F}$, significantly longer times were observed than for equivalent specimens aged about 12 weeks under similar temperature and humidity conditions. Duration of aging beyond 30 days in atmospheres below 85 percent relative humidity had no influence.

The data from the fire tests of neat gypsum, gypsum-perlite, and gypsum-vermiculite plasters served as bases for the calculation of estimates of the apparent thermal conductivities and thermal diffusivities of such plasters at temperatures in the range 1,200 to $1,500^{\circ} \mathrm{F}$. Values of the same thermal properties were obtained for steady-state heat flow at about $120{ }^{\circ} \mathrm{F}$ mean plaster temperature. No attempt was made to calculate values from the firetest data for the range 200 to $1,000{ }^{\circ} \mathrm{F}$ because of the latent heat effects associated with calcination of gypsum early in îre-test exposures. However, the values for higher temperatures, although only estimates, should be useful in the prediction of the fire endurances of plastered structures by analog: devices or computational procedures.

Examination of the data in terms of plaster thickness, over the small range of variation observed, showed agreement with the earlier indings from large specimen tests, so far as a limiting temperature rise is concerned. It is possible that large departures from the nominal 1-in. plaster thickness may affect the application of the high-temperature values of thermal properties, due to the effects resulting from the water in the hydrated gypsum.

The author expresses his appreciation to Garnett Robinson, who prepared the plaster bases and did the plastering.

\section{References}

[1] S. B. Hamilton, A short history of the structural fire protection of buildings, National Building Studies, Spec. Rept. No. 27, HMSO, London (1958).

[2] Standard methods of fire tests of building construction and materials, ASTM Designation E 119-58, American Society for Testing Materials, 1958 Book of Standards, Pt 5.

[3] K. K. Kelley, Contributions to the data on theoretical metallurgy, XIII. High-temperature heat-content, heat-capacity and entropy data for the elements and inorganic compounds, Bureau of Mines Bull. 585 (1960).

[4] Fire-resistance classifications of building constructions. NBS Building Materials and Structures Report 92 (1942).

[5] Proc. ASTM, Rept. of Subcommittee IV, of Committee C-8 on Refractories, 48, 259-260 (1948).

[6] Max Jakob, Heat Transfer, vol. 1, John Wiley \& Son, New York.

(Paper 66C4-113) 


\section{Publications of the National Bureau of Standards ${ }^{\star}$}

\section{Selected Abstracts}

Calorimetric calibration of an ionization chamber for determination of X-ray total beam energy, J. S. Pruitt and S. R. Domen, J. Research NBS $66 \mathbf{A}$ (Phys. and Chem.) No. 5, (Sept.-Oct. 1962). 70 cents.

The design and use of a high sensitivity lead calorimeter is described in this paper. It can measure the energy transported by an X-ray beam with an intensity as small as 2 microwatts $/ \mathrm{cm}^{2}$, and has been used to calibrate a duraluminum chamber developed in this laboratory with a maximum error of \pm 2 percent for all bremsstrahlung energies between 20 and $170 \mathrm{Mev}$. The results obtained are in excellent agreement with independent calibrations obtained with a scintillation spectrometer. The calibration of the copper chamber designed by Edwards and Kerst has also been determined over this energy range, to within \pm 2.6 percent, and agrees well with the high energy calibrations reported by these authors.

Effect of exposure site on weather resistance of porcelain enamels exposed for three years, D. G. Moore and A. Potter, NBS Mono. 44 (Apr. 10, 1962) 15 cents.

An exposure test of porcelain-enameled steel and aluminum specimens is being conducted jointly by the Porcelain Enamel Institute and the National Bureau of Standards. The exposure sites are Dallas, Tex.; Los Angeles, Calif.; New Orleans, La.; Pittsburgh, Pa.; Washington, D.C.; and two sites at Kure Beach, N.C.

The present report gives the results of the third-year inspection. Changes in gloss and color were taken as criteria of weathering. Based on averages for all enamels, the $80-\mathrm{ft}$ site at Kure Beach caused the greatest change in gloss and color, while the conditions at Dallas, Los Angeles, and New Orleans caused the least change. The conditions at Washington, Pittsburgh, and the second Kure Beach site $(800 \mathrm{ft}$ from the ocean) were of intermediate severity. Comparison of the gloss and color changes with data obtained by the Nationa Air Sampling Network indicated that air pollution by acidic contaminants was a factor in site severity.

A direct relation existed between acid resistance and weather resistance. This relation was apparent, however, only when averages were considered. There were individual exceptions within groups of enamels of the same general type. In addition, enamels of different types, such as aluminum and steel enamels, having the same acid resistance (citric acid spot test) did not necessarily show the same weather resistance. Further, some red and yellow enamels with good acid resistance showed poor color stability. It was found, however, that this poor stability could be predicted by a specially developed cupric sulfate test.

As a group, the regular glossy enamels for steel showed the best weather resistance among the various types tested.

Fire tests of precast cellular concrete floors and roofs, J. V. Ryan and E. W. Bender, NBS Mono. 45 (Apr. 12, 1962) 15 cents.

The results of an investigation of lightweight, precast cellular concrete planks are given. Fire tests were made of two floor and five roof specimens made up of these planks. Variables included density of the cellular concrete, thickness and span of the planks, reinforcement, and cover for the latter. A steel beam encased in blocks of cellular concrete was included in one floor specimen. The flexural strengths of 14 individual planks were determined. The investigation showed fire endurances up to $2 \mathrm{hr}$ for 6 -in. thick slabs tested under load and up to $4 \mathrm{hr}$ for other slabs not loaded. Estimates were made of the probable results to be expected for slabs of thicknesses other than those actually tested.
Structure shielding against fallout radiation from nuclear weapons, L. V. Spencer, NBS Mono. 42 (June 1, 1962) 75 cents. The theory of structure shielding from fallout gamma radiation is developed to the point of applications to elementary structure types. Examples discussed in the text include the density interface, foxhole, shielded foxhole or basement, light superstructure, vertical wall, blockhouse, vents, compartmentalization effects, and mazes. A large number of engineering charts and graphs are presented for engineering calculations, including many obtained from angular distributions of the exposure dose. Results are given for a fission spectrum, and for $\mathrm{Co}^{60}$ and $\mathrm{Cs}^{137}$ sources. This information has been obtained almost completely by machine calculations utilizing basic cross section data. A number of sources of experimental data are mentioned, but detailed comparisons with experiment are not included.

Basic magnetic quantities and the measurement of the magnetic properties of materials, R. L. Sanford and I. L. Cooter, NBS Mono. 47 (May 21, 1962) 30 cents.

This paper gives general information regarding the two basic quantities, magnetic induction, $B$, and magnetizing force, $H$, and also the magnetic constant $\Gamma_{m}$ (often designated by the symbols $\mu_{\nu}$ and $\mu_{o}$ ). Information is also given regarding the magnetic properties of various materials and methods and apparatus commonly used in the Magnetic Measurements Section for measuring these properties by means of reversed direct current or alternating currents of low frequency. Magnetic measurements peculiar to high frequencies are not discussed. In view of the gradual adoption of the rationalized mksa system of units, this system is included as well as the classical cgs electromagnetic system.

Determination of total X-ray beam energy with a calibrated ionization chamber, J. S. Pruitt and S. R. Domen, NBS Mono. 48 (June 5, 1962) 20 cents.

This report describes the use of an air-filled aluminum-alloy ionization chamber to determine the energy transported by a bremsstrahlung beam with maximum photon energy in the range 6 to $170 \mathrm{Mev}$. The experimental calibrations of this chamber over this energy range are given, as well as the results of calibration experiments made with a $250-\mathrm{kv}$ constantpotential X-ray tube and with $\mathrm{Cs}^{137}$ and $\mathrm{Co}^{60}$ gamma-rays. Information is presented about the change in calibration when the chamber is used with different experimental conditions, and when either its dimensions or its alloy composition are changed slightly. This report can be used to construct a replica chamber and to determine its absolute calibration between 6 and $170 \mathrm{Mev}$ under a variety of experimental conditions.

Some problems of fatigue of bolts and bolted joints in aircraft applications, L. Mordfin, NBS Tech. Note 136 (PB161637) (1962) \$1.25.

The profuse variety of aircraft bolts which is available has made the evaluation and specification of bolts for engine and structural use extremely complex, particularly insofar as fatigue and hot fatigue environments are concerned. The state of knowledge of fatigue of bolts and bolted joints is surveyed and critically appraised in terms of aeronautical practices. Using this material as a basis, recommendations are made regarding the evaluation and specification of aircraft bolts for fatigue situations and regarding the growing problem of errors in fastener replacement.

Cryogenic temperature measurement with platinum resistance thermometers - Is fixed-point calibration adequate? R. J. Corruccini, NBS Tech. Note 147 (PB161648) (1962) 50 cents. An analysis of extensive calibration data for strain-free "capsule"-type platinum resistance thermometers indicates that the above question can be answered affirmatively for 
temperatures down to $14^{\circ} \mathrm{K}$. For such thermometers, interpolation can be performed by a numerical procedure that makes use of similarities in the form of the departures of various thermometers from Matthiessen's rule. Where thermometers of more rugged construction or lower purity are concerned, the data needed to answer the question are not available. However, it is suggested that the answer may still be "yes" provided the thermometers are sufficiently uniform in their characteristics.

Characteristics of point-to-point tropospheric propagation and siting considerations, R. S. Kirby, P. L. Rice, and L. J. Maloney, NBS Tech. Note. 95 (PB161596) (1961) \$2.50.

This discussion is primarily intended to provide an understanding of the fundamental characteristics of tropospheric propagation with particular application to point-to-point telecommunications. The concept of service probability is introduced and its application to the planning of tropospheric circuits. This concept provides an objective means for taking into account the variables and uncertainties connected with a planned circuit so that a reasonable balance can be made between the cost of installation and operation as compared with the probability of success. Principles of siting based on taking advantage of favorable technical characteristics of the sites as well as associated considerations such as radiation hazards are discussed. Simple methods of making preliminary estimates of performance adequate for field use are presented.

OMNIFORM I: A general purpose machine program for the calculation of tables of functions given explicitly in terms of one variable, J. Hilsenrath and G. M. Galler, NBS Tech. Note 125 (PB161626) (1962) \$1.00.

A general purpose computer program, designed for use by non-programmers requiring computation of tables of functions written explicitly in terms of one variable, is described. The program features include: 22 types of elementary and special functions; provision for taking of functions of functions, table read-in, flexible print-out; and standardized input to a variety of problems. The use of the program is illustrated with a number of sample problems.

The thermodynamic properties of nitrogen from 64 to $300{ }^{\circ} \mathrm{K}$ between 0.1 and 200 atmospheres, T. R. Strobridge, NBS Tech. Note 129 (PB161630) (1962) \$2.25.

The internal energy, enthalpy, entropy, and specific volume of molecular nitrogen are derived and tabulated as functions of temperature and pressure. In addition to a mathematical model for the pressure-volume-temperature surface, accurate functions are given for the representation of the vapor pressure, density of saturated liquid, specific heat of saturated liquid, and the specific heat at zero pressure.

Tabular values in British units over the same pressure and temperature range are available as Supplement A of this Technical Note.

Detailed techniques for preparing and using hard gallium alloys, G. G. Harman, NBS Tech. Note 140 (PB161641) (1962) 75 cents.

This report presents an expansion and clarification of techniques for preparing and using dental-amalgam-type gallium alloys for industrial and scientific uses that were previously published in the Review of Scientific Instruments. In addition, new material, such as hardness of the alloys and discussions of the bonding mechanism are presented. A different class of bonding alloys based on the same principles but not incorporating gallium are described, along with application details.

Dielectric constant of liquid parahydrogen, R. J. Corruccini, NBS Tech. Note 144 (PB161645) (1962) 50 cents.

It is shown that the available data on the dielectric constant of hydrogen conform to the Clausius-Mossotti equation within the probable experimental errors. The published data cover temperatures from the triple point $\left(\sim 14{ }^{\circ} \mathrm{K}\right)$ to well above room temperature and a thousandfold range of densities. Using an average value of the specific polarization, tables of the dielectric constant of the liquid have been computed for temperatures from the triple point $\left(13.803{ }^{\circ} \mathrm{K}\right)$ to $32{ }^{\circ} \mathrm{K}$ $\left(58^{\circ} \mathrm{R}\right)$ and pressures from saturation to 340 atmospheres.
A wire exploder for generating cylindrical shock waves in a controlled atmosphere, D. L. Jones and K. B. Earnshaw, NBS Tech. Note 148 (PB161649) (1962) 50 cents.

A design for a rugged exploding wire device is given. This device permits the study of strong cylindrical shock waves in controlled atmospheres using optical and microwave techniques. Adequate detail and pictures are given to allow construction of the device.

Displacement and strain-energy distribution in a longitudinally vibrating cylindrical rod with a viscoelastic coating, P. Hertelendy, J. Appl. Mech. Trans. ASME 89, Series E, No. 1, 47-52 (Mar. 1962).

A numerical solution by R. M. Davies of the Pochhammer frequency equation is used to determine the displacement and strain energy distribution across the cross-section of an infinite elastic circular cylindrical rod for a number of wavelengths of the first, second, and third modes of symmetric longitudinal vibration. With these results the effect of a thin uniform layer of damping material on the surface is investigated, and it is shown that while first mode high frequency waves are damped out very rapidly, a large group of second and third mode waves experience virtually no damping.

Properties of silico-phosphate cements, J. N. Anderson and G. C. Paffenbarger, Dental Progress 2, No. 2, 72-75 (Jan. 1962).

Seven brands of silico-phosphate cements, recommended by their manufacturers as dental cementing media, were tested by standardized procedures (A.D.A. Specifications No. 8 and 9). Their use in some countries is accepted, but in others their value is questioned. About half of the cements tested did not set within 10 minutes. All had an excessive film thickness if mixed thick enough to have a proper setting time. The solubilities of the silico-phosphate cements in water is higher than those of the zinc phosphate cements. However, the silico-phosphate cements are not more soluble in the mouth since the solubility test is valid within a type of cement and cannot be used for intercomparison of dental cement based on phosphoric acid. The opacity of some of the cements is in the range of the opacities of enamel and dentin. The silico-phosphate cements are, therefore, the most suitable cementing media for translucent restorations.

Surface effect on bond strength of steel beams embedded in concrete, J. O. Bryson and R. G. Mathey, J. Am. Concrete Inst. 59, No. 3, 397-406 (Mar. 1962).

Wide flange structural steel beams with different surface conditions were embedded in concrete and subjected to pushout tests to determine the effect of the surface condition on the bond between the concrete and steel. The surfaces of the embedded steel beams were either freshly sandblasted, sandblasted and allowed to rust, or left with normal rust and mill scale.

The steel beams with a sandblasted surface, and those with a sandblasted surface which was allowed to rust, developed considerably higher ultimate bond stresses than beams with normal rust and mill scale. However, at a free end slip of $0.001 \mathrm{in}$. there was no significant difference in the bond stress for all three types of surface conditions.

Preparation of and electroplating on uranium, D. E. Couch, Plating 49, No. 4, 363-367 (A pr. 1962).

The black film that forms between uranium and coatings electrodeposited on it results from the solutions used in aqueous cleaning and plating procedures. It was eliminated by using a completely anhydrous plating solution. A porosity test, using hydrogen, was developed for testing the porosity of plated coatings on uranium.

Investigation of the spectrophotometric method of measuring the ferric ion yield in the ferrous sulfate dosimeter, K. Scharf and R. M. Lee, Radiation Research 16, No. 2, 115-124 (Feb. 1962).

The ferric ion vield produced by ionizing radiation in a ferrous sulfate dosimeter is usually determined by measuring the absorbance (optical density) of the irradiated solution at a wavelength of $304 \mathrm{~m} \mu$. The lowest absorbance which can be measured with sufficient accuracy sets the lower limit of 
the radiation dose which can be determined by this method. It was found that by measuring the absorbance at an absorption peak of $224 \mathrm{~m} \mu$, instead of at $304 \mathrm{~m} \mu$, the sensitivity of this method can be approximately doubled. This is due to the higher molar extinction coefficient of ferric ions at 224 $\mathrm{m} \mu$ which is 4565 liter $\mathrm{mole}^{-1} \mathrm{~cm}^{-1}$, as compared with a value of 2196 liter mole $\mathrm{e}^{-1} \mathrm{~cm}^{-1}$ at $304 \mathrm{~m} \mu$, both measured at $25{ }^{\circ} \mathrm{C}$. In the temperature range from $20{ }^{\circ} \mathrm{C}$ to $30{ }^{\circ} \mathrm{C}$, the value of the extinction coefficient at $25{ }^{\circ} \mathrm{C}$ changes by $.13 \%$ per degree at $224 \mathrm{~m} \mu$, compared with a change of $.69 \%$ at $304 \mathrm{~m} \mu$. The dependence of the extinction coefficient of ferric ions on the normality of the sulfuric acid (solvent) is less at $224 \mathrm{m \mu}$ than at $304 \mathrm{~m} \mu$. Values of the ferric ion yield produced by $\mathrm{Co}^{60}$ gamma rays, determined by measuring the absorbance at $304 \mathrm{~m} \mu$ and $224 \mathrm{~m} \mu$, agreed within experimental errors.

Tensile strength and modulus of elasticity of tooth structure and several restorative materials, R. L. Bowen and M. S. Rodriguez, J. Am. Dental Assoc. 64, No. 3, 278-287 (Mar. 1962).

Values for strength and modulus of elasticity were obtained in tension for various dental materials. The specimens were stored in distilled water at $99{ }^{\circ} \mathrm{F}$. for seven days. The specimens were loaded at 0.02 inches per minute head speed. Dentin and enamel specimens were prepared by cutting with rotating diamond tools using continuous water spray. They were formed into rectangular cross-section rods with a narrowed middle portion and notched ends, which were imbedded in direct filling resin. The materials had the following average tensile strength in pounds per square inch: enamel, 1,500; dentin, 7,500; silicate cements, 700; zinc phosphate cements, 500; direct filling resins, 4,200 and an experimental direct filling material containing about 70 percent treated fused silica, about 4,800 depending on surface treatment of the silica powder. The materials had the following average moduli of elasticity when measured in tension (times $10^{6}$ pounds per square inch): dentin, 2.8; a silicate cement, 3.1; direct filling resins, 0.27 and an experimental direct anterior filling material containing about 70 percent vinyl silane treated fused silica powder, 1.6.

Internal magnetic fields in nickel-rich nickel-cobalt alloys, L. H. Bennett and R. L. Streever, Jr., J. Appl. Phys. Suppl. 33, No. 3, 1093-1094 (Mar. 1962)

The nuclear magnetic resonances of both the $\mathrm{Ni}^{61}$ nuclei and the $\mathrm{Co}^{59}$ nuclei have been observed in a series of ferromagnetic nickel alloy powders containing up to 2.4 atomic percent cobalt. The room temperature value of the magnetic field at the site of the $\mathrm{Co}^{59}$ nucleus in any of these alloys is found to be about 111 koe. This is considerably smaller in magnitude than the magnetic field at the nickel site in either the alloy or in pure nickel, which, assuming a $\mathrm{Ni}^{61}$ nuclear moment of 0.30 nuclear magnetons, is about $170 \mathrm{koe}$, or at a cobalt site in pure cobalt, which is about 211 koe. The line widths of both the nickel and cobalt resonances increase with concentration with no detectable shift in frequency. The temperature dependence of the $\mathrm{Co}^{59}$ resonance frequency in the nickel - 0.6 percent cobalt alloy has been measured, and found to be different from that of $\mathrm{Ni}^{31}$ in pure nickel and in the alloy.

An aluminum magnet cooled with liquid hydrogen, J. R. Purcell, Proc. Intern. Conf. on High Magnetic Fields, Mass. Inst. of Tech., Cambridge, Mass., Nov. 1-4, 1961, pp. 166-169 (Mass. Inst. Tech. Press, Cambridge, Mass., and John Wiley \& Sons, Inc., New York, N.Y., 1962).

A high field, steady state magnet has been developed that utilizes liquid-hydrogen forced-convertion cooling. The solenoid is constructed of stacked reels wound with high purity aluminum foil, and employs unique radial ducts for coolant flow. This design allows for high stacking factor, low current requirements and simplicity of construction, along with a minimum of total power needs. The construction of the magnet and auxiliary equipment is described, and the results of preliminary testing are given.

Static dielectric constant of rutile $\left(\mathrm{TiO}_{2}\right), 1.6-1060{ }^{\circ} \mathrm{K}, \mathrm{R}$. A. Parker, Phys. Rev. 124, No. 6, 1719-1722'(Dec. 1961).

The static dielectric constant $\epsilon$ of rutile has been measured as a function of temperature from 1.6 to $1060{ }^{\circ} \mathrm{K}$. Rutile does not appear to be ferroelectric or antiferroelectric in this temperature range. At low temperatures, $\epsilon$ approaches a limiting value of 257 in the $c$-direction and 111 in the $a$-direction. $\epsilon_{300}{ }^{\circ} \mathrm{K}=170$ and 86 , respectively, and $\epsilon_{1000}{ }^{\circ} \mathrm{K}=97$ and 58. The ionic polarizability of titanium is calculated using the previously derived Lorentz correction in the rutile structure. The polarizability at all temperatures is very close to the critical value for a ferroelectric polarization catastrophe. The temperature variation of the ionic polarizability is explained qualitatively on the basis of other properties of the crystal.

Electronic conduction in rutile $\left(\mathrm{TiO}_{2}\right), \mathrm{H}$. P. R. Frederikse, W. R. Hosler, and J. S. Becker, Proc. Intern. Conf. Semiconductor Phys., Prague, Czechoslovakia, pp. 868-871 (1960). Measurements of conductivity, Hall effect and thermoelectric power performed on slightly reduced crystals of rutile can be explained with a model involving two conduction mechanisms: one of free electrons in a narrow 3d-band of titanium (above $5{ }^{\circ} \mathrm{K}$ ), and the other of self-trapped electrons or polarons in a polaron band (below $5{ }^{\circ} \mathrm{K}$ ). The ionization energy of the polaron increases from $\sim 0.01$ ev to 0.07 with increasing temperature.

Modulated photoelectric measurement of vibration, V. A Schmidt, S. Edelman, E. R. Smith, and E. T. Pierce, J. Acoust. Soc. Am. 34, No. 4, 455-458 (A pr. 1962).

This paper describes an improvement in the method of setting vibration amplitudes for calibrating vibration pickups by the disappearance of an interferometric fringe pattern. In the usual method, one plate of an interferometer is stationary, the other vibrates with the pickup, and the fringe pattern disappears at zeros of the Bessel function

$$
\frac{J_{0}(4 \pi \xi)}{\lambda}
$$

where $\xi$ is the amplitude of vibration and $\lambda$ is the wave length of light used. In the improved method, the fringes are observed by a photomultiplier, the previously stationary plate is vibrated at a modulating frequency much lower than the calibrating frequency applied to the pickup, and the signal from the photomultiplier, filtered at the modulating frequency, has minima at the zeros of $\frac{J_{0}(4 \pi \xi)}{\lambda}$ Observation of the nulls on a meter allows faster calibration with greater precision and less observer fatigue.

A high mode tunable cavity or microwave-gas interactions, A. J. Estin, Rev. Sci. Instr. 33, 369-371 (Mar. 1962).

A high- $Q$ resonant microwave cavity, operating in the $\mathrm{TE}_{01 n}(n=10,11)$ mode, is described. A fused quartz liner, with suitable inlet and pumping lines, is used to contain gases, so that interactions between the molecular transition. and the electromagnetic radiation can be generated Techniques are discussed for suppression of unwanted modes of oscillation, for dielectric tuning of the cavity, and for elimination of radiation through a large port.

Study of the effect of large aperture on the performance of an Ebert spectrometer, L. R. Megill and L. Doppleman, J. Opt. Soc. Am. 52, No. 3, 258-261 (Mar. 1962)

A description of the effect of large aperture upon the resolution limit of an Ebert spectrometer is discussed. The calculations were made by ray tracing on a high-speed computer. Variations of the aberration pattern at the exit slit are noted for several parameter changes which may be useful in design considerations.

Prediction of pressure drop in two-phase single-component fluid flow, M. R. Hatch and R. B. Jacobs, A. I. Ch. E. Journal 8, No. 1, 18-25 (Mar. 1962)

Data on pressure drop in two-phase, single-component fluid flow, both with and without heat transfer, are presented in terms of the Lockhart and Martinelli correlation parameters. The fluids used were trichloromonofluoromethane and hvdrogen.

The results are compared with the correlation curve recommended by Martinelli and Nelson and give frictional pressure drops that are about $40 \%$ lower than the curve. The reasons for the deviations are discussed in terms of the effects of 
friction factors, the existence of metastable equilibrium, accuracy of data and instrumentation, and calculation procedures.

It is concluded that the Martinelli and Nelson correlation and a simple momentum pressure drop computation can be superposed to predict roughly the total pressure drop in tubes containing steady state, two-phase, single-component fluid flow with appreciable vaporization.

Potential heat: A method for measuring the heat release of materials in building fires, J. J. Loftus, D. Gross, and A. F. Robertson, Am. Soc. Testing Materials Proc. 61, 1336-1348 (June 1961).

Modifications have been made to a method, currently a standard of the French government, for assessment of the combustible characteristics of building materials. This method makes use of standard calorimetric techniques in which the burning of small quantities of combustible in an otherwise inert material is assured by use of a combustion promoter which is added prior to test. By performing calorimetric measurements both before and after exposure to a "standardized fire" (two hours in air at $750{ }^{\circ} \mathrm{C}$ ) the difference may be considered as the potential heat. The test method has been used for measurement of the potential heat of a variety of building materials, including metals and materials of low combustibility, with results in general agreement with fire experience. A discussion is included on the precision of the test method.

Comparison of standard and microtests for international rubber hardness, R. D. Stiehler and F. L. Roth, Mater. Res. \& Std. (ASTM Bull.) 2, No. 5, 388-391 (May 1962).

The two standard testers for the determination of International Rubber Hardness described in ASTM Designation D 1415 were compared with an electronic microtester. Twenty-two rubber compounds ranging in hardness from about 30 to 90 International Rubber Hardness Degrees (IRHD) were used in the comparison. Results obtained with the three testers agreed within about one IRHD. The standard tester had slightly better precision, but a visual null indicator for the microtester should increase its precision. The microtester was more responsive to surface conditions (e.g., hardening caused by oxidation) and to non-uniformities in the rubber at or near the surface; this makes the instrument particularly useful in research investigations as well as for the measurement of hardness on small rubber parts. This comparison indicated that a microtest would be a valuable addition to ASTM Designation: D 1415.

Emission flame photometry, M. Margoshes, Anal. Chem. 34, No. 5, 221R-224R (Apr. 1962).

During the period covered in this review, the beginning of 1960 through February 1962, there has been some change in the emphasis of research in flame photometry. The interest in high temperature flames, such as cyanogen-oxygen, has lessened, while the application of organic solvents as a means of improving sensitivity has become more general. Methods have been developed for elimination of some anion interferences by means of releasing agents which prevent the formation of refractory compounds of the analytes. A number of papers on chemiluminescence have been presented at meetings, although little of this information has yet appeared in print.

The determination of sodium and potassium is still by far the most common use made of flame photometry. Because this area of application is so well established, very few of the papers reporting on sodium and potassium determinations are cited in this review.

Thermal explosives: adiabatic self-heating of explosive and propellants, D. Gross and A. B. Amster, Eighth Symp. (Intern.) on Combustion, $p p$. 728-734 (The Williams and Wilkins Co., Baltimore, Md., 1962).

An explosive may be defined as a substance in a metastable state of internal equilibrium which, being subjected to a comparatively small external activation, turns rapidly into a hot gas producing a very high local pressure. The sensitivity of an explosive is defined in terms of the magnitude of this activation, i.e., the greater the required activation, the less sensitive the material is said to be. Many different methods have been used to measure explosive sensitivity often with conflicting results. Any attempt to explain these anomalies leads to a requirement for knowledge of the thermal, thermochemical and kinetic properties of the systems involved. For a number of explosives and propellants, this paper reports some measurements of these properties and suggests a correlation with one type of sensitivity, namely sensitivity to impact.

Tungsten helical-spring microbalance, S. L. Madorsky' Vacuum Microbalance Techniques 2, 47-57 (Plenum Press, Inc., New York, N.Y., 1962).

This paper describes a helical spring microbalance, made of 30 mil tungsten wire and enclosed in a Pyrex glass housing. It was used in connection with a problem involving measurement of rates of thermal degradation of polymers in a vacuum by the loss-of-weight method. The balance has a sensitivity of about $550 \mu / \mathrm{mg}$ and is so constructed as to avoid errors that might be caused by the thermal expansion of its parts or of the supports holding the balance and the cathetometer used in connection with it.

Electrical properties of nonstoichiometric semiconductors, J. H. Becker and H. P. R. Frederikse, J. Appl. Phys. Suppl. 33, No. 1, 447-453 (Jan. 1962).

The electrical conductivity $\sigma$, thermoelectric power $Q$, and Hall coefficient $R$ are examined as a function of the ratio of hole-to-electron concentrations $p / n$ for a non-degenerate semiconductor at constant temperature. From these relations the fundamental parameters of the material (forbidden hand gap, mobilities and effective masses) can be derived. This approach is particularly applicable to materials whose stoichiometry varies as a function of temperature and vapor pressure of the constituents, $P$. For any model of this equilibrium decomposition, it is easy to transform the calculations in terms of $p / n$ into results as a function of $P$. As $p / n$ increases, $\sigma$ passes through a minimum, while $Q$ and $R$ traverse minimum (negative), zero, and maximum (positive) values. These extrema are of special interest. In the simple case of one kind of imperfection, $\sigma, Q$, and $R$ become independent of $P$ in a certain pressure range (i.e., when the intrinsic condition $n=p$ has been reached). It is then possible to derive the ratio of mobilities $\mu_{n} / \mu_{p}$ and the ratio of the average effective masses $m *_{n} / m{ }_{p}$ from $\sigma(P)$ and $Q(P)$ only. Hence, if $\mu_{n}$ or $m^{*}{ }_{p}$ are known (i.e., from measurements at lower temperatures), one can calculate these parameters for the other charge carrier.

\section{Other NBS Publications}

Journal of Research 66A (Phys. and Chem.) No. 5 (Sept.-Oct. 1962) 70 cents.

Calorimetric calibration of an ionization chamber for determination of X-ray total beam energy. J. S. Pruitt and S. R. Domen. (See above abstract.)

Zinc oxide as a standard substance in the solution calorimetry of portland cement. E. S. Newman.

Nuclear optical model analysis of neutron elastic scattering for calcium. R. S. Caswell.

Pyrolysis of some polyvinyl polymers at temperatures up to $1,200{ }^{\circ} \mathrm{C}$. S. Straus and S. L. Madorsky.

Lattice frequencies and rotational barriers for inorganic carbonates and nitrates from low temperature infrared spectroscopy. R. A. Schroeder, C. E. Weir, and E. R. Lippincott.

Foreign gas broadening of the lines of hydrogen chloride and carbon monoxide. E. K. Plyler and R. J. Thibault.

Monolayers of adipate polyesters at air-liquid interfaces. W. M. Lee, R. R. Stromberg, and J. L. Shereshefsky.

Journal of Research 66B (Math. and Math. Phys.) No. 3 (July-Sept. 1962), 75 cents.

The first run preceded by a quota. A. J. Goldman and B. K. Bender. 
Two theorems on matrices. M. Newman.

Mill's ratio for multivariate normal distributions. I. R. Savage.

Angle as a fourth fundamental quantity. J. E. Romain.

Invalidity of Meixner's theorem in irreversible thermodynamics. R. E. Nettleton.

Selected bibliography of statistical literature, 1930 to 1957: VI. Theory of estimation and testing of hypotheses, sampling distributions, and theory of sample surveys. L. S. Deming.

Journal of Research 66D (Radio Prop.) No. 5 (Sept.-Oct. 1962), 70 cents.

Theory of magneto-telluric fields. J. R. Wait.

Propagation characteristics of magneto-ionic plasma columns. D. Formato and A. Gilardini.

Dielectric loading of electric dipole antennas. J. Galejs.

Possible influence of the ionosphere on the impedance of a ground-based antenna. J. R. Wait.

Some statistical theory for the analysis of radio propagation data. M. M. Siddiqui.

Auroral sporadic- $E$ ionization. R. D. Hunsucker and L. Owren.

Comparative study of the correlation of seasonai and diurnal cycles of transhorizon radio transmission loss and surface refractivity. B. R. Bean.

Enhancement of the lunar tide in the noon critical frequency of the $F_{2}$ layer over the magnetic equator. R. G. Rastogi.

Scattering from a conducting sphere embedded in a semiinfinite dissipative medium. J. Galejs.

High-frequency scattering from a coated sphere. V. H. Weston and R. Hemenger.

Propagation of spherical waves through an ionosphere containing anisotropic irregularities. K. C. Yeh.

Tables of spectral-line intensities. Part I. Arranged by elements, W. F. Meggers, C. H. Corliss, and B. F. Scribner, NBS Mono. 32, Pt. I (Dec. 29, 1961) \$4.00.

Radiation patterns in the lower ionosphere and Fresnel zones for elevated antennas over a spherical earth, R. G. Merrill and W. V. Mansfield, NBS Mono. 38 (Apr. 2, 1962) 70 cents.

An ultraviolet multiplet table, C. E. Moore, NBS Circ. 488, Sections 3, 4, and 5 (Apr. 6, 1962) Section 3, 60 cents; Section 4, 45 cents; Section 5, 30 cents.

Specifications, tolerances, and regulations for commercial weighing and measuring devices (corrected through 1961) Handb. 44, 2d Ed. (1961) \$1.00.

Index to the reports of the National Conference on Weights and Measures. From the first to the forty-fifth, 1905 to 1960, NBS Misc. Publ. 243 (June 28, 1962) 30 cent (Supersedes M203).

Quarterly radio noise data-December, January, February 1961-62, W. Q. Crichlow, R. T. Disney, and M. A. Jenkins, NBS Tech. Note 18-13 (PB151377-13) (1962) \$1.75.

Mean electron density variarions of the quiet ionosphereSeptember 1959, J. W. Wright, L. R. Wescott, and D. J. Brown, NBS Tech. Note 40-7 (PB151399-7) (1962) $\$ 1.50$.

Mean electron density variations of the quiet ionosphere No. 13: Summary of one year of data, May 1959-April 1960 , J. W. Wright, NBS Tech. Note 40-13 (PB151399-13) (1962) $\$ 1.50$.

Bibliography on auroral radio wave propagation, W. Nupen, NBS Tech. Note 128 (PB161629) (1962) \$2.75.

Airborne television coverage in the presence of co-channel interference, M. T. Decker, NBS Tech. Note 134 (PB161635) (1962) $\$ 2.00$

Ionosonde observations of artificially produced electron clouds: Firefly 1960, J. W. Wright, NBS Tech. Note 135 (PB161636) (1962) \$2.50.

A bibliography of the thermophysical properties of oxygen at low temperatures, J. C. Hust, L. D. Wallace, J. A. Crim, L. A. Hall, and R. B. Stewart, NBS Tech. Note 137 (PB161638) (1962) $\$ 2.25$.

Vertical cross sections of the ionosphere across the geomagnetic equator, J. W. Wright, NBS Tech. Note 138 (PB161639) (1962) \$1.00.

Siting criteria for HF communication centers, W. F. Utlaut, NBS Tech. Note 139 (PB161640) (1962) \$1.25.
Atlas of Fourier coefficients of diurnal variation of foF 2, W. B. Jones, NBS Tech. Note 142 (PB161643) (1962) $\$ 2.50$.

Numerical results for the surface impedance of a stratified conductor, C. M. Jackson, J. R. Wait, and L. C. Walter, NBS Tech. Note 143 (PB161644) (1962) \$1.25.

Analysis of ionospheric vertical soundings for electron density profile data. III. Procedures for obtaining monthly summary virtual height curves for $\mathrm{N}(\mathrm{H})$ analysis (composite virtual height curves), J. W. Wright, NBS Tech. Note 146 (PB161647) (1962) 75 cents.

Dissociation constant of 2-ammonium-2-methyl-1,3-propanediol in water from 0 to $50^{\circ}$ and related thermodynamic quantities, H. B. Hetzer and R. G. Bates, J. Phys. Chem. 66, 308-311 (1962).

An introduction to flame photometry and a review of recent studies, M. Margoshes, Phys. Tech. Biological Research 4, 215-260 (1962)

Congruences for the partition function to composite moduli, M. Newman, Illinois J. Math. 6, No. 1, 59-63 (Mar. 1962).

Research and the saving of teeth, G. C. Paffenbarger, J. Prostetic Dentistry 12, No. 2, 369-383 (Mar-Apr. 1962).

Comments on paper by W. D. Westfall, "Prediction of VLF diurnal phase changes and solar flare effect." J. R. Wait, J. Geophys. Research 6\%, No. 2, 916-917 (Feb. 1962)

The shape of the geomagnetic field boundary under uniform external pressure, R. J. Slutz, J. Geophys. Research 67, No. 2, 505-513 (Feb. 1962).

Plating standards and specifications, F. Ogburn, Electroplating Eng. Handb. 2d ed., Ed. K. Graham, ch. 7, pp. 257-262 (Reinhold Publ. Co., New York, N.Y., 1962).

Inequalities for the permanent function, M. Marcus and M. Newman, Ann. Math. 75, No. 1, 47-62 (Jan. 1962).

Study of electronically excited hydroxyl radicals in the $\mathrm{H}+\mathrm{O}_{3}$ atomic flame, H. P. Broida, J. Chem. Phys. 36, No. 2, 444-448 (Jan. 1962).

Theory of thermal diffusion in dilute alloys, R. E. Howard and J. R. Manning, J. Chem. Phys. 36, No. 4, 910-916 (Feb. 1962).

Effect of monomeric reagents on the melting (contraction) and recrystallization of fibrous proteins, L. Mandelkern, W. T. Meyer, and A. F. Diorio, J. Phys. Chem. 66, 375-376 (1962).

A correction to the exospheric electron density estimate using the nose whistlers of March 19, 1959, J. H. Pope, J. Geophys. Research 67, No. 1, 412 (Jan. 1962).

Hydrogen formation in the gamma-radiolysis of ethylene, P. Ausloos and R. Gorden, Jr., J. Chem. Phys. 36, No. 1, 5-9 (Jan. 1962)

Microwave spectrum and nonplanarity of cyanamide, D. J. Millen, G. Topping, and D. R. Lide, Jr., J. Mol. Spectroscopy 8, No. 2, 153-163 (Feb. 1962).

Long-distance one-hop $F_{1}$ propagation through the auroral zone, L. H. Tveten, J. Geophys. Research 66, No. 6, 16831684 (June 1961).

Impurity effects in high purity metal, L. L. Wyman and G. A. Moore (Symp. Major Effects of Minor Constituents on the Properties of Materials. Sixty-fourth annual meeting ASTM, Altantic City, N. J., June 26, 1961), ASTM Spec. Tech. Publ. No. 304-ASTM Material Sci. Series 2, 3-16 (June 26, 1961).

Vibration-rotation interactions in cyanamide; the question of planarity of amides, D. R. Lide, Jr., J. Mol. Spectroscopy 8, No. 2, 142-152 (Feb. 1962).

Vacuum ultraviolet photochemistry. III. Primary processes in the vacuum ultraviolet photolysis of water and ammonia, J. R. McNesby, I. Tanaka, and H. Okabe, J. Chem. Phys. 36, No. 3, 605-607 (Feb. 1962).

Accuracy of analytical procedures, W. J. Youden, J. Assoc. Official Agricultural Chemists 45, No. 1, 160-173 (Feb. 1962).

Vacuum microbalance techniques, R. F. Walker, Ed., Vol. 2, 179 pages, Proc. Conf. at the National Bureau of Standards, Apr. 20-21, 1961 (Plenum Press, New York, N.Y., 1962).

First pulsed radio soundings of the topside of the ionosphere, R. W. Knecht and T. E. Van Zandt, J. Geophys. Research 66, No. 9, 3078-3081 (Sept. 1961).

Cryogenics and nuclear physics, R. P. Hudson, Science 134, 1733-1736 (Dec. 1961). 
Vacuum ultraviolet photochemistrv. II. Photolysis of ethylene, H. Okabe and J. R. MeNesby, J. Chem. Phys. 36, No. 3, 601-604 (Feb. 1962).

Experimental study of the stark broadening of the Balmer lines $\mathrm{H} \gamma$, W. L. Wiese, D. R. Paquette, and J. E. Solarski, Proc. Fifth Intern. Conf. Ionization Phenomena in Gases, Munich, pp. 907-912 (North Holland Publ. Co., Amsterdam, The Netherlands, 1961).

Strong blast waves in spherical, cylindrical and plane shocks, D. L. Jones, Phys. of Fluids 4, No. 9 (Sept. 1961).

Approximations to the moments of the sample median, M. M. Siddiqui, Ann. Math. Stat. 33, No. 1, 157-168 (Mar. 1962).

Kinetic equation for plasmas with collective and collisional correlations, C. M. Tchen, Proc. Fifth Conf. on Ionization Phenomena in Gases, Munich, pp. 825-841 (North Holland Publ. Co., Amsterdam, The Netherlands, 1961).

Plasma with net charge, J. L. Jackson, D. B. Levine, and R. A. Piccirelli, Phys. of Fluids 5, No. 2, 250-251 (Feb. 1962).

Solubility product phenomena in hydroxypatite-water systems, H. M. Rootare, V. R. Deitz, and F. G. Carpenter, J. Colloid. Sci. 17, No. 3, 179-206 (Mar. 1962).

Worldwide patterns of ionospheric blackout occurrence, V. Agy and K. Davies, J. Atmospheric and Terrest. Phys. 23, 202-205 (Dec. 1961).

Fluorescence and rotational relaxation of $\mathrm{OH}$ radicals in flames, T. Carrington, Eighth Symp. (Intern.) on Combustion, pp. 257-262 (The Williams \& Wilkins Co., Baltimore, Md., 1960).

Refraction effects of large-scale ionospheric irregularities observed at Boulder, Colorado, R. S. Lawrence and J. L. Jespersen (Proc. 2d Intern. Space Science Symp., Florence, Italy, Apr. 10-14, 1961), Space Research II, 258-276 (North Holland Publ. Co., Amsterdam, The Netherlands, Apr. 1961).

Physical properties of 113 domestic marbles, A. Hockman, Ärchitectural Record, pp. 192-193 (Apr. 1962).

On the nature of equatorial slant sporadic E, R. Cohen, K. L. Bowles, and W. Calvert, J. Geophys. Research 67, No. 3, 965-972 (Mar. 1962).

A survey of carbon-carbon bond lengths, D. R. Lide, Jr., Tetrahedron 17, 125-134 (1962).

I. Strange sounds in the atmosphere, R. K. Cook, Sound-Its Uses and Control 1, No. 2, 12-16 (Mar.-Apr. 1962).

Possible solar flare effects in the $\mathrm{F}$ region of the ionosphere, R. W. Knecht and K. Davies, Nature 192, No. 4800, 347-348 (Oct. 1961).

Microwave structure determinations on tertiary butyl acetylene and tertiary butyl cyanide, L. J. Nugent, D. E. Mann, and D. R. Lide, Jr., J. Chem. Phys. 36, No. 4, 965-971 (Feb. 1962).

Translational energy accommodation in the nickel-chlorine surface reaction, J. D. McKinley, J. Phys. Chem. 66, 554-555 (Mar. 1962)

Auroral-zone geomagnetic micropulsations with periods of 5 to 30 seconds, W. H. Campbell and S. Matshushita, J. Geophys. Research 6\%, No. 2, 555-573 (Feb. 1962).

Some problems of color identification, K. L. Kelly, J. Am. Inst. Architects 3\%, No. 3, 80-82, (Mar. 1962).

Lorentz corrections in rutile, R. A. Parker, Phys. Rev. 124, No. 6, 1713-1719 (Dec. 1961).

Some observations of $2.89 \mathrm{Mc} / \mathrm{s}$ equivalent antenna temperatures at the auroral zone, C. G. Little, G. M. Lerfald, and R. Parthasarathy, J. Atmospheric and Terrest. Phys. 23, 275-286 (Dec. 1961).

The structure of regions of coronal-line emission, J. T. Jefferies, C. W. Pecker, and R. N. Thomas, Astrophys. J. 135, 653-655 (Mar. 1962).
A digital ray-tracing program for ionosphere research, R. S. Lawrence and D. J. Posakony, (Proc. 2d Intern. Space Science Symp.. Florence, Italy, Apr. 10-14, 1961), Space Research II, 258-276 (North Holland Publ. Co., Amsterdam, The Netherlands, Apr. 1961).

Pulsed radio soundings of the topside of the ionosphere in the presence of spread F, R. W. Knecht and S. Russell, J. Geophys. Research 6\%, No. 3, 1178-1182 (Mar. 1962).

Recent studies on rutile $\left(\mathrm{TiO}_{2}\right), \mathrm{H}$. P. R. Frederikse, J. Appl. Phys. Suppl. 32, No. 10, 2211-2215 (Oct. 1961).

The resistive transition in $\mathrm{Nb}_{3} \mathrm{Sn}, \mathrm{D}$. Cline, R. H. Kropschot, V. Arp, and J. H. Wilson, Proc. Internl. Conf. on High Magnetic Fields, Mass. Inst. Tech., Cambridge, Mass., Nov. 1-4, 1961, pp. 580-583 (Mass. Inst. Tech., Press, Cambridge, Mass., and John Wiley \& Sons, Inc., New York, N.Y., 1962).

Structure and photodetachment spectrum of the atomic carbon negative ion, M. L. Seman and L. M. Branscomb, Phys. Rev. 125, No. 5, 1602-1608 (Mar. 1962).

Propagation of the low frequency radio signal, J. R. Johler, Proc. IRE 50, 404-427 (Apr. 1962).

Utilization of tritium and carbon-14 in studies of isotope effects, H. S. Isbell, H. L. Frush, and L. T. Sniegoski, Book, Tritium in the Physical and Biological Sciences II, 94-101 (International Atomic Energy Agency, Vienna, Austria, 1962).

A statistical comparison of the wearing characteristics of two types of dollar notes, E. B. Randall, Jr., and J. Mandel, Mater. Res. \& Std. (ASTM Bull.) 2, No. 1, 17-20 (Jan. 1962).

Comments on "Effects of ultrahigh pressures on glass," C. E. Weir and S. Spinner, .I. Am. Ceram. Soc. 45, No. 4, 196 (Apr. 1962).

The "vicious cycle" in secondary batteries - a mathematical approach, W. G. Eicke, Jr., J. Electrochem. Soc. 109, No. 5, 364-368 (May 1962).

Communication between man and machine, S. N. Alexander and J. E. Karlin, Proc. IRE 50, No. 5, 1124-1128 (May 1962).

Entropies, heats of sublimation and dissociation energies of the cesium halides, M. D. Scheer and J. Fine, J. Chem. Phys. 36, No. 6, 1647-1753 (Mar. 15, 1962).

The radio refractive index of air, B. R. Bean, Proc. IRE 50, No. 3, 260-273 (Mar. 1962).

The reflection of logistics in electronic computer design, E. W. Cannon, Naval Research Logistics Quart. $7,365-371$ (1960)

Deactivation of $\mathrm{Hg}\left(6^{3} \mathrm{P}_{1}\right)$ by $\mathrm{CO}$ and $\mathrm{N}_{2}, \mathrm{M}$. D. Scheer and J. Fine, J. Chem. Phys. 36, No. 5, 1264-1267 (Mar. 1962).

Variability of spectral tristimulus values, I. Nimeroff, J. Opt. Soc. Am. 52, No. 6, 685-691 (June 1962).

The propagation of electromagnetic waves along the earth's surface, J. R. Wait, Book, Electromagnetic Waves, Ed. by R. E. Langer, p. 243 (The University of Wisconsin Press, Madison Wisc., 1962).

An auroral-zone electron precipitation event and its relationship to a magnetic bay, R. R. Brown and W. H. Campbell, J. Geophys. Research 6\%, No. 4, 1357-1366 (Apr. 1962).

*Publications for which a price is indicated (except for Technical Notes) are available only from the Superintendent of Documents, U.S. Government Printing Office, Washington 25, D.C. (foreign postage, one-fourth additional). Technical Notes are available only from the Office of Technical Services, U.S. Department of Commerce, Washington 25, D.C. (order by PB number). Reprints from outside journals and the NBS Journal of Research may often be obtained directly from the authors. 